\title{
Marine phospholipids: The current understanding of their oxidation mechanisms and potential uses for food fortification
}

\author{
Lu, Henna Fung Sieng; Nielsen, Nina Skall; Baron, Caroline P.; Jacobsen, Charlotte
}

Published in:

Critical Reviews in Food Science and Nutrition

Link to article, DOI:

$10.1080 / 10408398.2014 .925422$

Publication date:

2017

Document Version

Peer reviewed version

Link back to DTU Orbit

Citation (APA):

Lu, H. F. S., Nielsen, N. S., Baron, C. P., \& Jacobsen, C. (2017). Marine phospholipids: The current understanding of their oxidation mechanisms and potential uses for food fortification. Critical Reviews in Food Science and Nutrition, 57(10), 2057-2070. https://doi.org/10.1080/10408398.2014.925422

\section{General rights}

Copyright and moral rights for the publications made accessible in the public portal are retained by the authors and/or other copyright owners and it is a condition of accessing publications that users recognise and abide by the legal requirements associated with these rights.

- Users may download and print one copy of any publication from the public portal for the purpose of private study or research.

- You may not further distribute the material or use it for any profit-making activity or commercial gain

- You may freely distribute the URL identifying the publication in the public portal 


\section{Marine Phospholipids: The Current Understanding of Their Oxidation Mechanisms and Potential Uses for Food Fortification}

Article in Critical reviews in food science and nutrition · November 2015

DOI: 10.1080/10408398.2014.925422

4 authors:

Henna Fung Sieng Lu

Kalsec Inc.

21 PUBLICATIONS 241 CITATIONS

SEE PROFILE

Caroline P Baron

Technical University of Denmark

50 PUBLICATIONS $\mathbf{1 , 4 8 0}$ CITATIONS

SEE PROFILE
Nina Skall Nielsen

Technical University of Denmark

72 PUBLICATIONS 1,451 CITATIONS

SEE PROFILE

Charlotte Jacobsen

Technical University of Denmark 221 PUBLICATIONS 4,183 CITATIONS

SEE PROFILE

Some of the authors of this publication are also working on these related projects:

Project UNCOVER View project

Project $\quad$ Krill project View project 


\title{
Critical Reviews in Food Science and Nutrition
}

\section{Marine Phospholipids: The Current Understanding of Their Oxidation Mechanisms and Potential Uses for Food Fortification}

\author{
F. S. H. Lu, N. S. Nielsen, C. P. Baron \& C. Jacobsen
}

To cite this article: F. S. H. Lu, N. S. Nielsen, C. P. Baron \& C. Jacobsen (2015): Marine Phospholipids: The Current Understanding of Their Oxidation Mechanisms and Potential Uses for Food Fortification, Critical Reviews in Food Science and Nutrition, DOI: 10.1080/10408398.2014.925422

To link to this article: http://dx.doi.org/10.1080/10408398.2014.925422

Accepted author version posted online: 11 Nov 2015.

Submit your article to this journal ¿

Џ Article views: 11

View related articles \ulcorner

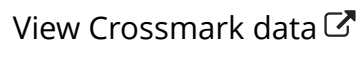




\title{
ACCEPTED MANUSCRIPT
}

\section{Marine Phospholipids: The Current Understanding of their Oxidation Mechanisms and Potential Uses for Food Fortification}

\author{
Lu, F. S. H., Nielsen, N. S., Baron, C. P., Jacobsen, C. \\ Division of Industrial Food Research, Technical University of Denmark, Søltofts Plads, Building \\ 221, 2800 Kgs. Lyngby, Denmark. \\ Running title: Lipid oxidation and non-enzymatic browning of marine phospholipids. \\ Keywords: Marine phospholipids, oxidative stability, Strecker degradation, primary amine \\ group, pyrroles, polymerization.
}

\section{Corresponding author.}

Tel: +4545254938 ; fax: +4545884774

Email: fshl@food.dtu.dk, Henna Fung Sieng Lu

\begin{abstract}
:
There is a growing interest in using marine phospholipids (PL) as ingredient for food fortification due to their numerous health benefits. However, the use of marine PL for food fortification is a challenge due to the complex nature of the degradation products that are formed during the handling and storage of marine PL. For example, non-enzymatic browning reactions
\end{abstract}




\section{ACCEPTED MANUSCRIPT}

may occur between lipid oxidation products and primary amine group from phosphatidylethanolamine or amino acid residues that are present in marine PL. Therefore, marine PL contain products from non-enzymatic browning and lipid oxidation reactions, namely Strecker aldehydes, pyrroles, oxypolymers, and other impurities that may positively or negatively affect the oxidative stability and quality of marine PL. This review was undertaken to provide the industry and academia with an overview of the current understanding of the quality changes taking place in PL during their production and their storage as well as with regards to their utilisation for food fortification. 


\section{ACCEPTED MANUSCRIPT}

\section{INTRODUCTION}

Marine phospholipids (PL) are different from PL derived from other sources such as soybean, egg yolk, etc. Most of the PL derived from marine sources, especially phosphatidylcholine (PC) has a polyunsaturated fatty acid (PUFA) at sn-2 position of its glycerol backbone. According to Le Grandois and co-workers (2009), the most dominant PL molecular species in marine sources such as Antartic krill are C16:0-20:5 PC and C16:0-22:6 PC and therefore these marine PL are rich in eicosapentaenoic acid (EPA, C20:5) and docosahexaenoic acid (DHA, C22:6). In general, PC is the most abundant PL derived from marine sources such as salmon, tuna, rainbow trout, blue mackerel, bonito, herring etc. The second abundant PL is phosphatidylethanolamine (PE) and followed by other minor PL such as phosphatidylinositol (PI), phosphatidylserine (PS), sphingomyelin (SPM) and lyso-PC. PL derived from marine sources have been the focus of much attention recently. Many studies have shown that marine PL provide more advantages than fish oil containing only triglyceride (TAG). These advantages include: i) a higher content of physiologically important n-3 long chain (LC) PUFA such as EPA and DHA (Peng et al., 2003);

ii) a better bioavailability of EPA and DHA (Wijendran et al., 2002); iii) a broader spectrum of health benefits including those from n-3 LC PUFA, their polar head groups and the combination of the two in the same molecule (Ierna et al., 2010); iv) a better resistance towards oxidation (Cho et al., 2001; Moriya et al., 2007). Nevertheless, it is important to note that the oxidative stability of marine PL is influenced by other factors such as purity, presence of other residues and structures that PL can be formed in different matrix such as micelles, liposomes, etc. 


\section{ACCEPTED MANUSCRIPT}

Due to the numerous advantages of marine PL, there is a growing awareness of using marine PL as ingredient for food fortification. Marine PL contain a high level of PC, which has amphiphilic properties and therefore they are potential natural surfactants for emulsion preparation. Furthermore, marine PL emulsions could be used as effective carriers of n-3 LC PUFA rich oil as they could be incorporated easily into aqueous and emulsified foods. To date, many studies on n-3 TAG fortified functional foods are available in literature, whereas food fortification with marine PL is a new area in food industry. Only several studies have been carried out to investigate the potential use of marine PL (Lu et al., 2013b) and krill oil (which comprises approximately 30-40\% PL) for food fortification (Pietrowski et al., 2011; Kassis et al., 2010, 2011; Sedoski et al., 2012). Nevertheless, these studies reported that both marine PL and krill oil fortified foods are still susceptible to oxidation due to the high content of n-3 LC PUFA in marine PL and krill oil. Therefore, the oxidative stability of marine PL and krill oil in real food systems need to be further investigated. Information on the oxidative stability of marine PL are scarcely available except a few studies on marine PL based liposomes (Mozuraityte et al., 2006a, 2006b, 2008), marine PL liposomes under gastrointestinal condition (Cansell et al., 2001;

Nacka et al., 2001a, 2001b) and several studies on marine PL emulsions and krill oil from our laboratory (Lu et al., 2012a, 2012b, 2012c, 2013a, 2013b, 2014; Thomsen et al., 2013).

In addition, the composition of marine PL and krill oil are more complex than TAG fish oil as they are not refined and deodorized as fish oils are. Due to the presence of the primary amine group from PE or amino acids and carbonyl groups, non-enzymatic browning reactions were observed in marine PL, marine PL emulsions and also in krill oil (Lu et al., 2012b, 2014). This observation was substantiated by several other studies, which also reported the occurrence 


\section{ACCEPTED MANUSCRIPT}

of non-enzymatic browning reactions in model system or matrix containing primary amine groups and lipid oxidation products (Hidalgo et al., 2003, 2005a, 2005b, 2006, 2007). The interaction between non-enzymatic browning reactions and lipid oxidation may complicate the study of oxidative stability of marine PL. Therefore, the main objectives of this review study are to provide food industries and academia with: a) new insights into the lipid oxidation and nonenzymatic browning reactions in marine PL, b) suggestions to improve the quality of current marine PL, and c) insight into the potential use of marine PL for food fortification.

\section{OXIDATION OF MARINE PHOSPHOLIPIDS}

PL are degraded through two main pathways of hydrolysis and/or oxidation. Hydrolysis usually occurs in the presence of water to produce lysophospholipids and free fatty acids. Lysophospholipids are subsequently degraded to glycerophospho compounds as the end product of PL hydrolysis. In addition, PL hydrolysis is catalysed under either basic or acid conditions (Gritt et al., 1993). On the other hand, the PL degradation via oxidation of its fatty acids is similar to other lipids. There are several proposed mechanisms for lipid oxidation, namely lipid autoxidation, photoxidation, and enzymatic or non-enzymatic oxidation. The discussion of photoxidation and enzymatic oxidation for marine PL is beyond the scope of this review paper. Therefore, the discussion of this part will mainly focus on autoxidation of marine PL with special emphasis on n-3 LC PUFA (EPA and DHA).

Similar to the oxidation of TAG in fish oil, the n-3 LC PUFA chains in marine PL are the primary targets of oxidation. Autoxidation of n-3 LC PUFA in PL occurs via a free radical chain reaction that can be divided into 3 stages, namely initiation, propagation and termination. A 


\section{ACCEPTED MANUSCRIPT}

simplified scheme of lipid autoxidation is given in Figure 1. Autoxidation of lipids produce a great variety of compounds with different polarities, stabilities and molecular weights. These compounds can be classified as three main groups as suggested by Dobarganes and MarquezRuiz (2007): a) compounds with molecular weights similar to those of the unsaturated lipid molecules (LH) but with one of their fatty acids undergone oxidation, b) volatile compounds such as aldehydes, hydrocarbons, alcohols and ketones, c) oxypolymerization compounds such as dimers or polymers, which are formed through the interactions of two or more lipid radicals $\left(\mathrm{L}^{\bullet}\right)$ and therefore they have higher molecular weights than the initial lipid LH. Dimers and polymers are large molecules that are formed by a combination of $-\mathrm{C}-\mathrm{C}-,-\mathrm{C}-\mathrm{O}-\mathrm{C}-$ and $-\mathrm{C}-\mathrm{O}-\mathrm{O}-$ C- bonds (Kim et al., 1999). They have either acyclic or cyclic structures depending on the reaction process and types of fatty acids in lipids (Tompkins and Perkins, 2000). Oxypolymerisation usually occurs at high temperature or at the accelerated stage of oxidation when the solubility of oxygen decreases drastically and most of the hydroperoxides (LOOH) decomposed to form peroxyl $\left(\mathrm{LOO}^{\bullet}\right)$ and alkoxyl radicals $\left(\mathrm{LO}^{\bullet}\right)$. Oxypolymers are formed through reaction mainly involving alkyl radicals $\left(\mathrm{L}^{\bullet}\right)$ and alkoxyl radicals $\left(\mathrm{LO}^{\bullet}\right)$. According to Khayat and Schwall (1983), oxypolymerisation of lipid oxidation products generated from highly unsaturated fatty acids produced brown colored oxypolymers.

Lipids are susceptible toward oxidation in the presence of catalysts/initiators such as transition metals (iron and copper). The presence of transition metal in marine PL is an important factor decreasing the oxidative stability of marine PL. Transition metals such as ferrous and

ferric ions $\left(\mathrm{Fe}^{2+}\right.$ and $\left.\mathrm{Fe}^{3+}\right)$, primarily promote lipid oxidation by decomposing lipid hydroperoxide into free radical via a Fenton-type reaction as suggested by Dunford (1987). 


\section{ACCEPTED MANUSCRIPT}

Therefore, lipid oxidation could be greatly suppressed when the level of hydroperoxides was reduced in model system as suggested by Tadolini and Hakim (1996). In addition, the type, concentration and chemical state of transition metal may influence the decomposition rate of hydroperoxides differently. For instance, ferrous ion is a stronger pro-oxidant than ferric ion due to its higher solubility and reactivity (Halliwell and Gutteridge, 1990). Transition metals decompose hydroperoxides $(\mathrm{LOOH})$ to form alkoxy radical $\left(\mathrm{LO}^{\bullet}\right)$ and peroxyl radicals $\left(\mathrm{LOO}^{\bullet}\right)$, which can then abstract further $\mathrm{H}$ atoms. Free radicals $\left(\mathrm{L}^{\bullet}\right)$ can then react with triplet oxygen to form peroxyl radicals. In addition, transition metals can also abstract $\mathrm{H}$ from unsaturated lipid $(\mathrm{LH})$ to form free radical $\left(\mathrm{L}^{\bullet}\right)$, but this reaction is relatively slow and therefore is not an important pathway of lipid oxidation (Reische et al., 2008).

\section{Formation of secondary volatile oxidation products in marine $P L$}

Under certain conditions such as high temperature and the presence of transition metal ions, unstable lipid hydroperoxides may decompose through the formation of peroxyl and alkoxyl radicals, and cleavage of the alkoxyl radicals by homolytic $\beta$-scission to form a wide variety of shorter-chain secondary oxidation volatiles. To the best of our knowledge, study on the characterizations of marine PL derived volatiles is scarcely available in the literature except several studies from our laboratory (Lu et al., 2012b, 2012c, 2013a, 2013b). Due to the high content of n-3 LC PUFA in marine PL, we obtained an almost similar lipid derived volatile profile as fish oil for marine PL emulsions. Several studies have investigated the secondary volatiles derived from n-3 LC PUFA in bulk fish oil system (Karahadian et al., 1989; Aidos et 


\section{ACCEPTED MANUSCRIPT}

al., 2002) and real food systems such as milk, mayonnaise, etc (Hartvigsen et al., 2000; Venkateshwarlu et al., 2004; Sørensen et al., 2010a, 2010b). Some of the selected n-3 LC PUFA derived volatiles and their associated odours with comparison to those from marine PL are listed in Table 1. Although the primary oxidation products of n-3 LC PUFA themselves are tasteless and odourless, decomposition of these products such as ketones and aldehydes that have low odour thresholds may adversely affect the flavour, taste and overall quality of foods containing n-3 PUFA. For instance, volatiles such as 1-penten-3-one, (Z)-4-heptenal, 1-octen-3-one, 1,5octadien-3-one, (E,E)-2,4-heptadienal, and (E,Z)-2,6-nonadienal derived from n-3 LC PUFA have been reported as the most potent odorants in fish oil. Despite the potency of these volatiles, none of this individual volatile but rather a combination of volatiles is responsible for a fishy or metallic off-flavour in fish oil enriched milk (Venkateshwarlu et al., 2004). As mentioned earlier, marine PL have been shown to have a more complex matrix than fish oil as marine PL may contain amino acids residues or protein in addition to the high n-3 PUFA content in glycerophospholipids (Lu et al., 2012b). Therefore, marine PL have been shown to have a broader spectrum of secondary volatiles, including those derived from n-3 LC PUFA and those from non-enzymatic reactions.

\section{NON-ENZYMATIC BROWNING IN MARINE PL}

The most common non-enzymatic browning reactions is the Maillard reaction. It is a usually described as reaction between a reactive carbonyl group from reducing sugar with a nucleophilic amino group from amino acid. In addition to the reactive carbonyls from sugar or carbohydrates, lipid oxidation also produces reactive $\alpha$-dicarbonyls that can be engaged in non- 


\section{ACCEPTED MANUSCRIPT}

enzymatic browning reactions as reviewed by several studies (Pokorny and Sakurai, 2002; Zamora and Hidalgo, 2005, 2011). This review was undertaken to discuss the non-enzymatic browning reactions in marine PL from the aspect of lipid oxidation. Therefore, the discussion of browning development in marine PL which may be due to the other factors such as the presence of reducing sugar or microbial mediated enzymatic reactions is beyond the scope of this review paper. In general, non-enzymatic browning reactions in marine PL can be divided into two groups a) pyrrolisation to form pyrroles and b) Strecker degradation of amino acids if amino acid residues are present in marine PL (as shown in Figure 2a). Studies on non-enzymatic browning in marine PL system are scarcely available in the literature. Only a few studies on non-enzymatic browning in marine PL liposomes were reported by Thanonkaew et al $(2005,2006 \mathrm{a}, 2006 \mathrm{~b}$, 2007). These studies investigated non-enzymatic browning reactions only from the aspect of lipid oxidation and pyrrolisation. However, new findings on non-enzymatic browning reaction in marine PL emulsions and krill oil including both pyrrolisation and Strecker degradation were reported by our recent studies (Lu et al., 2012b, 2012c, 2013a, 2014). The selected volatiles derived from non-enzymatic browning reactions as reported by our studies with reference to other studies are shown in Table 2.

\section{Proposed mechanisms for non-enzymatic browning reactions in marine PL}

Based on several studies by Hidalgo and co-workers (Hidalgo and Zamora, 2004, 2005; Zamora and Hidalgo, 2005, 2011), several pathways were proposed for non-enzymatic browning reactions in marine PL (as shown in Figure 2). It is suggested that extraction of PL at high temperature in the production of marine PL causes lipid oxidation and forms firstly secondary volatile oxidation products/carbonyl compounds and subsequently tertiary lipid oxidation 


\section{ACCEPTED MANUSCRIPT}

products ( $\alpha$-dicarbonyl derivatives analogous to that of carbohydrate). Tertiary lipid oxidation products such as unsaturated epoxy keto fatty esters, epoxyalkenals and hydroxyalkenals are reactive toward primary amine group that are present in marine PL (Zamora et al., 2007; Rizzi, 2008). An example of tertiary lipid oxidation products is 4,5-(E)-epoxy-2-(E)-heptenal with two oxygenated function groups. This epoxyalkenal was derived from secondary oxidation product, (E,E)-2,4-heptadienal. Zamora and co-workers (2007) suggested that the presence of two oxygenated, namely one carbonyl group and one epoxy or hydroxyl group is required for the Strecker degradation and pyrrolisation to occur.

\section{Strecker degradation:}

Strecker degradation is a minor pathway in non-enzymatic browning and involves the oxidative deamination of $\alpha$-amino acids in the presence of compound such as reducing sugars, lipid oxidation products, dehydroascorbic acid, quinones or other Strecker reagents (Rizzi, 2008; Zamora and Hidalgo, 2011). In marine PL, it is suggested that tertiary lipid oxidation products firstly react with amino acids to form an imine (as shown in Figure 2a and 2b, mechanism A). This imine undergoes rearrangement, decarboxylation, hydrolysis and subsequently evolves into a Strecker aldehyde and a hydroxyl amino compound, hydroxyl amino compound is responsible for the formation of 2-alkylpyridines (Hidalgo and Zamora, 2004, 2005). Therefore, if this reaction occur between an epoxyalkenal (4,5-(E)-epoxy-2-(E)-heptenal) and an amino acid (leucine) in marine PL, a Strecker aldehyde (3-methybutanal) and 2-methylpyridine could be produced. Moreover, it is suggested that secondary lipid oxidation products could also degrade amino acids to their corresponding Strecker degradation products. Zamora and co-workers 


\section{ACCEPTED MANUSCRIPT}

(2007) investigated the Strecker degradation of amino acids (phenylalanine) in aqueous medium by using secondary lipid oxidation products (alkadienals and ketodienes) at $180^{\circ} \mathrm{C}$. Their findings showed that alkadienals and ketodienes are not the final lipid oxidation products in this reaction. Alkadienals and ketodienes could degrade amino acids to their corresponding Strecker degradation products when they are pre-oxidized to an epoxyalkenal prior to the ensuing Strecker degradation.

\section{Pyrrolisation}

In addition to Strecker degradation, pyrrolisation is another alternative pathway for lipid oxidation products and primary amine group. Firstly, tertiary lipid oxidation products react with the amine groups to produce an imine, which then evolves into a cyclic intermediate (as shown in Figure 2b). This intermediate subsequently is converted into two different pyrrole derivatives and a short chain aldehyde depending on the reaction conditions, namely 2-(1hydroxyalkyl)pyrroles and $\mathrm{N}$-substituted pyrroles. Formation of 2-(1-hydroxyalkyl)pyrroles is always accompanied by a formation of $N$-substituted pyrroles (Zamora and Hidalgo 1994, 1995). As far as the stability is concerned, $N$-substituted pyrroles are stable, whereas 2-(1-hydroxyalkyl) pyrroles are unstable. 2-(1-hydroxyalkyl) pyrroles polymerize spontaneously to form melanoidin/lipofuscin-like macromolecules and therefore cause non-enzymatic browning development (as shown in Figure 2a and 2c). Polymerization occurs by successive dehydrations between the polymers and the monomers, and may also include other pyrroles. Pyrrolisation could occur between lipid oxidation products with PE or amino acids/protein residues. As shown in Figure 2a (mechanism B and C), if a reaction takes place between tertiary lipid oxidation 


\section{ACCEPTED MANUSCRIPT}

products with PE, the pyrroles produced are most likely to be hydrophobic, but if a reaction takes place with amino group of amino acids or protein, the pyrroles produced are most likely to be hydrophilic. This hypothesis was further supported by the findings in Lu et al (2013a), which showed that hydrophilic pyrroles were found only in PL liposomal dispersion with amino acids added (Figure 3a), whereas hydrophobic pyrroles were found only in dispersions containing PE after incubation at $60{ }^{\circ} \mathrm{C}$ for 6 days (Figure 3b). In addition, the formation of hydrophobic pyrroles from PE pyrrolisation was further confirmed by the PE losses, which was observed in liposomal dispersion after incubation (Figure 3c). Between PE and amino acids, the amino group of PE undergoes pyrrolization 10 times more readily than the amino group of amino acids. This is due to the close proximity of the generation place of lipid oxidation products to the amino group of PE (Zamora et al., 2005).

\section{Oxypolymerisation}

As mentioned earlier, oxypolymerisation of lipid oxidation products might form brown colored polymers. Therefore, the presence of oxypolymer might be another reason for browning development in marine PL. Our most recent study (Lu et al., 2013a) showed that browning development in liposomal dispersion prepared from PC (which has a DHA at sn-2 position) was attributed to oxypolymerisation as PC do not contain primary amine and therefore no pyrroles were found in this liposomal dispersion (as shown in Figure $3 \mathrm{a}$ and $3 \mathrm{~b}$ ). In contrast, browning development in dispersion containing PE was attributed to both hydrophobic pyrrole formation and oxypolymerisation (as shown in Figure $3 \mathrm{~b}$ and $3 \mathrm{~d}$ ). However, further investigation is required to find out which reaction, pyrrolisation or oxypolymerisation contributes more to 


\section{ACCEPTED MANUSCRIPT}

browning development in marine PL. As a summary, the browning development in marine PL might be attributed to the presence of both oxypolymers and pyrrole polymers. The issue of pyrrolisation will be further discussed in the later part of this paper.

Comparison with other studies (formation of furans, pyridines, pyrazines and their alkyl substituents)

Several more recent studies of Adams and co-workers (Adams et al., 2009, 2011a, 2011b) proposed different mechanisms for non-enzymatic browning reactions (aldol condensation of $\alpha, \beta$-unsaturated aldehydes and this process was strongly catalyzed by the presence of amino acids). Their model systems comprise amino acids (glycine or lysine) and $\alpha, \beta$-unsaturated aldehydes $((E)$-2-hexenal and (E,E)-2,4-decadienal) in anhydrous medium with and without addition of glucose. After incubation at $125^{\circ} \mathrm{C}$ or $200^{\circ} \mathrm{C}$ for $120 \mathrm{~min}$., melanoidin like polycondensation products such as furans, pyridines, pyrroles, pyrazines and benzene derivatives were found in these systems (Adams et al., 2009). Different from the mechanisms proposed by Hidalgo and co-workers, their findings showed that the formation of 2-alkylpyridine required no compound with two oxygenated function groups. For instance, an alkylpyridine (5-butyl-2propylpyridine) was found in the model system comprising (E)-2-hexenal and amino acids (glycine or lysine). They proposed that this compound was formed through condensation of two molecules of (E)-2-hexenal with $\mathrm{NH}_{3}$ through a Michael type addition toward a second molecule of $(E)$-2-hexenal. After rearrangement of the double bound and cyclization, alkylpyridine was formed after elimination of water (as shown in Figure 4a). The same mechanism was also applied for model system comprising (E,E)-2,4-decadienal to form 2-pentypyridines. However, it 


\section{ACCEPTED MANUSCRIPT}

is worth noting that the Hidalgo and co-workers investigated the Strecker degradation of amino acids in aqueous medium at much lower temperature, whereas Adam and co-worker investigated the reaction in anhydrous medium at much higher temperature. For instance, Hidalgo and Zamora (2004) reported the formation of phenylacetaldehyde and 2-alkylpyridines in aqueous system comprising 4,5-(E)-epoxy-2-(E)-heptenal and phenylalanine after incubation at $37{ }^{\circ} \mathrm{C}$, or in aqueous system comprising 4-hydroxy-2-nonenal and phenylalanine after incubation at 37 or 60 and $80{ }^{\circ} \mathrm{C}$.

In another study of Adams and co-workers (2011b), they investigated the formation of 2alkylfuran from lipid derived $\alpha, \beta$-unsaturated aldehydes under dry roasting condition $\left(180{ }^{\circ} \mathrm{C}\right.$ for $20 \mathrm{~min}$ ). Their findings showed that the presence of amino acids, peptides and proteins induced non-enzymatic browning reactions and catalyzed the formation of 2 -alkylfuran from $\alpha, \beta$ unsaturated aldehydes. However, they suggested that intermediate compounds with two oxygenated function groups such as 4-hydroxy-2-alkenals were formed prior to their intramolecular cyclization into 2-alkylfuran. They also reported that an oxidizing condition and involvement of radicals were required for 2-alkylfuran formation (as shown in Figure 4b). For instance, the addition of an aqueous oxidizing $\mathrm{CuCl}_{2}$ solution, the presence of oxygen and radical initiator significantly enhanced the formation of 2-alkylfuran. With respect to pyridines and pyrazines formation, several earlier studies in the literature suggested that ammonia or hydrogen sulphide, which were generated via degradation of amino acids after incubation at high temperature $\left(140\right.$ or $180^{\circ} \mathrm{C}$ for 1 hour) might contribute to the formation of pyridines and pyrazines in model system containing $\alpha$-dicarbonyl/carbonyl compounds (Farmer and Mottram, 1990; Hwang et al., 1993; Kim et al., 1996). Pyridines could be formed when ammonia or amino 


\section{ACCEPTED MANUSCRIPT}

acids react with carbonyl compounds such as unsaturated aldehydes derived mainly from lipid oxidation (Kim et al., 1996; Kim and Ho, 1998).

On the other hand, pyrazines could be formed when ammonia or amino acids react with $\alpha$-dicarbonyl compounds to form $\alpha$-amino carbonyl compound, which is the precursor for pyrazine formation. Both carbohydrate and lipid could be the source for $\alpha$-dicarbonyl compounds in marine PL. It is no doubt that $\alpha$-amino carbonyl compounds could be formed through the Strecker degradation of amino acids by methylglyoxal or glyoxal ( $\alpha$-dicarbonyl compound derived from sugar or carbohydrates). Nevertheless, methylglyoxal and glyoxal have been shown to be lipid oxidation products in system containing no reducing sugar (Zamora and Hidalgo, 2005; Mlakar and Spiteller, 1995; Loidl-Stahlhofen and Spiteller, 1994). Therefore, formation of pyrazines in marine PL is partly attributed to the presence of lipid oxidation products. In addition, Negroni, D'Agostina, and Arnoldi (2001) reported that the presence of lipid oxidation products greatly influenced the formation of pyrazines in model system containing vegetable oils, lysine, xylose and glucose. In addition, it is important to note that pyrazines formation in marine PL could be associated with the incomplete removal of shell during marine PL manufacturing process. Our previous study reported that the formation of pyrazines and its alkyl substituents in krill oil was partly attributed to the presence of residual krill shell in krill oil (Lu et al., 2004).

The most accepted mechanism for pyrazine formation was firstly reported by Shibamoto and co-workers (1979) and later by Adam and co-workers in 2008. Adam et al (2008) reported that the incubation of an anhydrous medium comprising various amino acids and 1,3dihydroxyacetone as a precursor of methylglyoxal at $90^{\circ} \mathrm{C}$ for $30 \mathrm{~min}$ led to the formation of pyrazine. They proposed that pyrazine formation involved the condensation of two $\alpha$-amino 


\section{ACCEPTED MANUSCRIPT}

carbonyl compounds to form dihydropyrazine, which later oxidized to form pyrazine. Subsequently, the incorporation of Strecker aldehyde or other aldol condensation products in the intermediate dihydropyrazine might occur to form other less abundant pyrazine with additional substituents (Figure 4c). In general, different proposed mechanisms for non-enzymatic browning reactions could be found in the literature. Due to the present of various non-enzymatic browning products in marine PL, it is suggested that more than one chemical pathways are involved for their formation. Therefore, more studies are required in future to further investigate these complex mechanisms in marine PL.

Strecker degradation in marine PL

In marine PL, Strecker degradation may occur between lipid oxidation products and amino acids. Our recent study showed that more than ten different types of Strecker degradation products were found in emulsions prepared from marine PL through solid phase microextraction (SPME) GC-MS and dynamic headspacce (DHS) GC-MS determination (Table 2). Several studies (Flores et al., 1998; Ventanas et al., 2007; Lu et al., 2013a) suggested that 2-methylbutanal and 3-methylbutanal are Strecker degradation products from isoleucine or leucine, respectively. Dimethylsulphide, dimethyldisulphide and dimethyl trisulphide might be degraded from sulphur containing compounds such as methionine or cysteine (Methven et al., 2007; Ventanas et al., 2007; Lu et al., 2013a). It is important to note that the presence of sulphur containing compounds in marine PL might also be associated with phytoplankton, which could be degraded to form dimethyl sulfide as exemplified in krill oil. As suggested by Budzinski and co-workers (1985), the presence of sulphur containing compounds in krill products might be attributed to the disintegration of whole intact krill (including its digestive tract, where phytoplankton was 


\section{ACCEPTED MANUSCRIPT}

accumulated) during their manufacturing process. On the other hand, 2-methyl-2-pentenal and 2methyl-2-butenal were suggested to be the major volatiles resulting from a reaction between (E,E)-2,4-heptadienal with a lysine (Zamora and Hidalgo., 1994). To the best of our knowledge, the study by Lu et al (2012b) was the first to report the generation of Strecker degradation products in marine PL emulsions. The most dominant Strecker degradation products in marine PL emulsions are 3-methylbutanal, dimethyldisulphide and 2-methyl-2-pentenal, respectively (Lu et al., 2012b). The hypothesis that amino acids were involved in the formation of Strecker degradation products in marine PL was supported by the detection of amino acids in marine PL preparations in our recent study (Lu et al., 2012b). Moreover, our recent study also showed that Strecker degradation products of amino acids only were found in liposomal dispersions to which amino acids were added or in dispersions containing PE (as shown in Figure 3e). The high level of Strecker degradation products found in marine PL emulsions could be attributed to the high level of amino acid residues in marine PL used for emulsions preparation (Lu et al., 2012b, 2012c). Among the measured Strecker degradation products, some of them slightly increased in marine PL emulsions after 32 days storage at $2{ }^{\circ} \mathrm{C}$. Therefore, Strecker degradation might occur at low reaction rate in marine PL emulsions during their storage at low temperature as shown by our recent studies (Lu et al., 2012b, 2012c). However, most of the Strecker degradation reaction seemed to occur in marine PL during their manufacturing process which involves high temperature (Lu et al., 2012b).

Pyrrolisation in marine PL 


\section{ACCEPTED MANUSCRIPT}

Thanonkaew and co-workers (2006b) had investigated the impact of lipid oxidation on yellow pigment formation in squid (Loligo peali) lipids and proteins. Their studies suggested that lipid oxidation increased simultaneously with browning development and pyrroles content, and correlated with a concomitent decrease in free amines when squid microsomes, squid PL liposomes and egg yolk lecithin liposomes were oxidized under pro-oxidative conditions. They also reported that the occurrence of non-enzymatic browning in squid muscle could primarily be ascribed to the reaction between the amine groups of PE and aldehydic lipid oxidation products. In fact, their findings are in agreement with that of Zamora and co-workers (Zamora et al., 2000, 2004). Zamora et al (2000) reported that a high correlation was obtained among the measurements of color, fluorescence and pyrroles in model systems comprising 4,5(E)-epoxy-2(E)-heptenal/lysine or linolenic acid/lysine after incubation at $37{ }^{\circ} \mathrm{C}$ and $60{ }^{\circ} \mathrm{C}$. The color and fluorescence production in these model systems was due to the pyrrole formation and polymerization. On the other hand, Zamora et al (2004) showed that pyrrolization of PL contributed to the oil darkening in poorly degummed edible oils, refined olive and soybean oils.

Thanonkaew and co-workers (2006b) also suggested that the degree of unsaturation affected the degree of non-enzymatic browning reactions in liposomes as proven by a higher degree of non-enzymatic browning reactions in squid PL liposomes compared to egg yolk lecithin. These findings are in agreement with that of Uematsu and co-workers (2002), who also reported an increase in browning development as the degree of unsaturation increased. When egg yolk lecithin liposomes were incubated with different aldehydic lipid oxidation products at $37^{\circ} \mathrm{C}$ for 15 hours, they found that the saturated aldehydes, namely propanal and hexanal had the least impact on yellowness and chemical properties of liposomes. In contrast, the monounsaturated 


\section{ACCEPTED MANUSCRIPT}

and polyunsaturated aldehydes especially $(E)$-2-heptenal, $(E)$-2-octenal and $(E, E)$-2,4-hexadienal increased significantly the yellowness, free amines and pyrroles content of liposomes. Another study from this group reported that the increase of incubation temperature or time led to an increase of lipid oxidation, pyrrolization and browning development in cuttlefish liposomes with a coincidental decrease in amine groups (Thanonkaew et al., 2007). The above-mentioned findings were further supported by our latest finding, which also showed that the increase in lipid oxidation led to an increase in pyrroles formation in liposomal dispersions prepared from purified marine PL after 6 days incubation at $40{ }^{\circ} \mathrm{C}$ (Lu et al., 2013a). It is worth noting that no pyrroles were found in above mentioned dispersion before incubation and that pyrroles were being formed as incubation was progressing. In addition, our other study showed that pyrroles were found mainly in marine PL preparations, which were extracted at high temperature, whereas a much lower level of pyrroles was found in marine PL, which were produced through enzymatic hydrolysis at low temperature (Lu et al., 2012b). As shown in Figure 5, different levels of pyrroles were found in emulsions ( $\mathrm{A}, \mathrm{B}$ and $\mathrm{C}$ ) preparing from different marine $\mathrm{PL}$ preparations. Furthermore, the level of hydrophobic pyrroles was generally higher than hydrophilic pyrroles in marine PL. However, there was no increment of pyrroles before and after 32 days storage of these emulsions at $2^{\circ} \mathrm{C}$. This phenomenon might imply that temperature is an important factor influencing the pyrrolisation in marine PL.

\section{Antioxidative properties of pyrroles}

Pyrroles formed between oxidized lipids and the amine groups of protein/amino acids were shown to have antioxidative properties (Alaiz et al., 1995a, 1995b). However, the antioxidative 


\section{ACCEPTED MANUSCRIPT}

activity of pyrroles produced during the oxidative process was significantly increased with the addition of artificial antioxidants such as BHT or $\alpha$-tocopherol (Ahmad et al., 1998) or decreased due to the pyrrole polymerization (Anese and Nicoli, 2003; Hidalgo et al., 2003). The effect of pyrrole polymerization on the antioxidative activity of non-enzymatic browning reactions has been well studied by Hidalgo and co-workers (2003). In the first part of this study, they investigated the antioxidative activities of eight different pyrroles. According to their findings, antioxidative activity exhibited by pyrroles could be categorized into 3 main groups and was in the order stated as follows: a) pyrroles with no free $\alpha$ position > pyrroles with free $\alpha$ position > pyrroles with an oxygenated group. In other words, the antioxidative activity of pyrrole derivatives was in the order stated as follows: 1,2,5-trimethylpyrrole and 2,5-dimethylpyrrole > pyrrole and 1-methylpyrrole > 2-acetylpyrrole, 2-acetyl-1-methylpyrrole, pyrrole-2carboxaldehyde and 1-methyl-2-pyrrolecarboxaldehyde. The structures of these molecules are shown in Figure 6.

In the second part, they investigated the changes in antioxidative activity during the polymerization of 2-(1-hydroxyethyl)-1-methylpyrrole (HMP). They reported that HMP firstly produced dimers (DIM), consequently both HMP and DIM polymerized to produce trimers (TRI), tetramers (TET) and higher polymers. They also reported that polymerization produced mainly the DIM rather than the higher polymers. In addition, polymerization contributed to the development of yellow color. As the incubation progressed, these DIM were transformed into polymers, and therefore their antioxidative activity decreased. Furthermore, DIM were found to be 2.5 times more antioxidative than HMP. Dimers contained two pyrrole rings without oxygenated functions and one of them having no free $\alpha$-position. In summary, their studies 


\section{ACCEPTED MANUSCRIPT}

showed that the antioxidative activity observed in a non-enzymatic browning reaction is the sum of the antioxidative activities of the different compounds present in the samples. Thus, antioxidative activity of a non-enzymatic browning reaction might change at the same time when the different pyrroles are either being produced or evolved into polymers.

Other studies on pyrroles particularly focusing on antioxidative activity of pyrroles in oxidized PL were reported by Hidalgo and co-workers (2005b; 2006; 2007). Hidalgo et al. (2005b) investigated the antioxidative activities of native and oxidized soybean phosphatiylcholine (PC), phosphatidylethanolamine (PE) and phosphatidyinositiol (PI) in protection of soybean oil heated in darkness under air at $60{ }^{\circ} \mathrm{C}$. They reported that the slightly oxidized PE was more antioxidative than the native PE due to the pyrroles formation in pyrrolized PE. The oxidized PL without an amine group such as PC and PI were less antioxidative than their native form as they did not produce pyrroles while they were being consumed during the oxidation.

\section{Interaction between lipid oxidation and non-enzymatic browning in marine $P L$}

As described above, lipid oxidation firstly produces oxidation products that subsequently react with primary amine group to produce Strecker degradation products or antioxidative compounds (pyrroles) through non-enzymatic browning reactions ( $\mathrm{Lu}$ et al., 2012b). Then, the produced antioxidative compounds may inhibit the lipid oxidation in marine PL. Lipid oxidation and nonenzymatic browning reactions are closely linked in marine PL system as in other systems where both lipids and amine groups are present. For instance, a low level of secondary volatile oxidation products (namely $(E, E)$-2,4-heptadienal and (E,Z)-2,6-nonadienal) was observed in 


\section{ACCEPTED MANUSCRIPT}

emulsions prepared from marine PL might be attributed to the interaction of lipid oxidation products with residues amino acids in marine PL to form pyrroles as suggested in Lu et al (2012b). This hypothesis was further supported by the findings from our model study (Lu et al., 2013a), which showed a gradual decrease or disappearance of lipid oxidation products was found in PL liposomal dispersions containing amino acids as non-enzymatic browning reactions progressed. The findings from our studies are in agreement with the findings of several other studies (Baek and Cadwallader, 1996; Ventanas et al., 2007).

Baek and Cadwallader (1996) analyzed the volatile profile of crayfish hydrolysate preparing from alkaline protease at $65{ }^{\circ} \mathrm{C}$ for 2.5 hours. They reported that Strecker derived volatiles, namely thermally generated volatiles such as dimethyl disulphide, dimethyl trisulphide, benzaldehyde and 2,5-dimethylpyrazine increased significantly after enzymatic hydrolysis of crayfish by products. In contrast, lipid derived volatiles, namely $(E, E)$-2,4-hexadienal, $(E, E)-2,4-$ heptadienal, (E,Z)-2,6-nonadienal, etc significantly decreased. They also reported that the increase of Strecker derived volatiles in crayfish hydrolysate might be attributed to the increase of amino acids and peptides after enzymatic hydrolysis and consequently increased the nonenzymatic browning reactions. In addition, they reported that the antioxidative compounds produced from enzymatic browning reactions might decrease the lipid oxidation at later stage and thereby decrease the generation of lipid derived volatiles. Ventanas and co-workers (2007) studied the lipid oxidation and non-enzymatic browning development in sterile meat model systems preparing from polar lipid liposomes with and without addition of selected amino acids. These model systems were then stored for 35 days storage at $25{ }^{\circ} \mathrm{C}$ under pro-oxidative conditions. Their findings showed that Strecker derived volatiles were found predominantly in 


\section{ACCEPTED MANUSCRIPT}

model systems containing both amino acids and liposomes prepared from polar lipids. In addition, Strecker derived volatiles were found to increase whereas lipid derived volatiles were found to decrease over time.

\section{HYPOTHESES REGARDING THE HIGH OXIDATIVE STABILITY OF MARINE PL}

The issue on oxidative stability of marine PL has been discussed extensively in our previous review paper (Lu et al., 2011). Therefore, only a brief summary of this issue is given here together with the latest findings from our laboratory As also reviewed in Lu et al. (2011), the high oxidative stability in marine PL is attributed to several hypothesized factors: a) The presence of a PUFA at the sn-2 position of PL, which could provide tightly packed molecular conformation if marine PL are used to prepare liposomes (Applegate and Glomset 1986; Miyashita et al., 1994; Nara et al., 1997, 1998). For instance, salmon roe PC was found to contain mainly 1-palmitoyl-2-PUFA-phosphatidylcholine, whereas soybean PC contains mainly 1, 2-dilinoleoyl-phosphatidylcholine (Miyashita et al., 1994). Therefore, it is difficult for free radicals and oxygen to attack PUFA in bilayer of tighter conformation in marine PC liposome as compared to that of soybean PC. This finding was further supported by the recent findings from our laboratory (Lu et al., 2012a, 2012b), which showed that marine PL dispersions/emulsions containing a high level of purified marine PL were less oxidized than those containing a low level of purified marine PL. It is because a larger population of liposomes, which are thermodynamically stable could be formed and thereby increase the oxidative stability of these dispersions (Lu et al., 2012a, 2012b). 


\section{ACCEPTED MANUSCRIPT}

b) The presence of both PL and $\alpha$-tocopherol increases oxidative stability of marine PL as reported by several studies (Bandarra et al., 1999; Cho et al., 2001; Moriya et al., 2007; Weng and Gordon, 1993). Our recent studies showed that a high oxidative stability was obtained for emulsion prepared from marine PL with a high level of $\alpha$-tocopherol ( $\mathrm{Lu}$ et al., 2012b). The same observation was obtained for dispersion prepared from purified marine PL with addition of $\alpha$-tocopherol and not for dispersion prepared with the same level of PL but without $\alpha$-tocopherol (Lu et al., 2012c). This indicated that $\alpha$-tocopherol is an efficient antioxidant to maintain the high oxidative stability of marine PL (Lu et al., 2012b, 2012c). Lu et al. (2012c) also reported that the induction period of purified marine PL decreased drastically after acetone precipitation due to the removal of $\alpha$-tocopherol. These findings are in agreement with that of Hidalgo and coworkers (2007), who also reported the high efficiency of $\alpha$-tocopherol as antioxidant to improve the antioxidant activity of oxidized PE.

c) The presence of pyrroles might also contribute to the oxidative stability of marine PL as discussed above. Several studies reported that the antioxidative property of pyrroles in marine PL was significantly improved with the present of $\alpha$-tocopherol (Hidalgo et al., 2007; Lu et al., 2012c). However, it cannot be ruled out that the oxidative stability of marine PL is also influenced by the presence of other compounds such as astaxanthin, coenzyme Q10, lutein, cholesterol and residue amino acids (Moriya et al., 2007; Lu et al., 2012b). Several amino acids have been shown to have antioxidant properties (Chen et al., 1996; Guo et al., 2009). In addition, our recent studies showed that the presence of cholesterol in marine PL could improve both the physical and oxidative stabilities of marine PL emulsions (Lu et al., 2012a, 2012b). Cholesterol has a condensing effect on the PC liposome (Finean, 1990). It could increase the rigidity of 'fluid 


\section{ACCEPTED MANUSCRIPT}

state' liposomal bilayers and thus improve the oxidative stability of liposomes (Fiorentini et al., 1989). In addition, the presence of pro-oxidants such as transition metals and initial hydroperoxide is an important factor influencing the oxidative stability of marine PL. As a summary, the oxidative stability of marine PL seems to be influenced by several factors: the level of PL (especially PC), antioxidants ( $\alpha$-tocopherol and pyrroles), pro-oxidants (transition metals and initial hydroperoxides) and other impurities (residues of amino acids) as observed in our recent studies (Lu et al., 2012a, 2012b, 2012c). It is also worth noting that a selection of appropriate methods is important to obtain a real picture of lipid oxidation in marine PL. For instance, the classic techniques which involve the measurement of primary and secondary lipid oxidation products such as Peroxide and Anisidine measurements were found to underestimate the lipid oxidation in krill oil as reported in our recent study (Thomsen et al., 2013; Lu et al., 2014). These techniques did not quantify the products formed from non-enzymatic browning reactions and their formation might partly consume the lipid oxidation products generated in krill oil. Therefore, more advanced techniques such as the measurement of both lipid and Strecker derived volatiles by dynamic headspace (DHS-GC/MS) or thermal desorption unit (TDUGC/MS) are recommended to investigate the oxidative stability of marine PL.

\section{Impact of matrix: lipid oxidation in marine PL emulsions and liposomes}

The mechanism of lipid oxidation in the o/w emulsion is different from the bulk oil system. This is because an o/w emulsion has an aqueous phase which contains both prooxidants and antioxidants, and an oil-water interface where the interactions between oil phase and prooxidants in aqueous phase may be enhanced (McClements and Decker, 2000). Some studies (Cercaci et 


\section{ACCEPTED MANUSCRIPT}

al., 2007; Chee et al., 2006) reported that the lipid is oxidized faster in o/w emulsions than bulk oil. This is because the emulsification process itself might promote oxidation and the presence of interfacial phases in o/w emulsions might also increase the interactions between lipid phase and pro-oxidant compounds in aqueous phase. In contrast, several studies (Belhaj et al., 2010; Garcia et al., 2006) reported that emulsification improved the oxidative stability of n-3 fatty acids oils due to the possibilities of using a) hydrophobic antioxidant which were more efficient in emulsions system, b) emulsifiers such as maltodextrin or PL which have antioxidative properties.

Even though marine PL were shown to have a high oxidative stability (King et al., 1992a, 1992b; Boyd et al., 1998, Belhaj et al., 2010), the oxidative stability of marine PL emulsions/dispersions was influenced by the quality, chemical composition and source of marine PL used (Lu et al., 2012b, 2012c). For instance, marine PL were found to contain pro-oxidant impurities such as free fatty acids, hydroperoxides, transition metals and etc. The presence of free fatty acids may promote lipid oxidation in marine PL o/w emulsions through their ability to increase the negative charge of the emulsion droplets and thus increase the metal-lipid interactions (Waraho et al., 2011). Several studies (Mei et al., 1998a, 1998b; Minotti and Aust, 1989) suggested that the interactions between lipid hydroperoxides, which are located at the surface of droplets with the transition metals originating in the aqueous phase is the most common cause of lipid oxidation. For instance, a study of Mozuraityte and co-workers (2006a) showed that the lipid oxidation rate as measured by oxygen consumption increased immediately in liposome dispersion prepared from cod PL after addition of transition metal, ferrous ions $\left(\mathrm{Fe}^{2+}\right)$. This phenomenon is due to the fast fixation of $\mathrm{Fe}^{2+}$ to the negative surface charge of PL liposome. 


\section{ACCEPTED MANUSCRIPT}

\section{POTENTIAL USE OF MARINE PL FOR FOOD APPLICATIONS}

The use of marine PL for food fortification is a new challenge in food industries. This is due to the presence of brown pigments such as pyrroles/oxypolymer (products of non-enzymatic browning reactions), dark red pigment (astaxanthin in krill PL) and unpleasant odor in most of the current marine PL that are available in the market. As mentioned earlier, only few studies on krill oil fortification are available in the literature (Kassis et al., 2010, 2011; Pietrowski et al., 2011; Sedoski et al., 2012). For instance, fortification of surimi seafood with n-3 fatty acids rich oils, namely flaxseed, algae, menhaden, krill and a blend of these oils has been reported (Pietrowski et al., 2011). They reported that fortification of surimi seafood product with krill oil increased the susceptibility of fortified product towards lipid oxidation. This phenomenon was due to the high content of EPA and DHA in krill oil, however the lipid oxidation of the fortified product was still within ranges acceptable to consumers. In addition, the above research group also studied the sensory properties, lipid composition and antioxidant capacity of novel nutraceutical egg products fortified with the same n-3 fatty acids rich oils as mentioned earlier (Kassis et al., 2011; Sedoski et al., 2012). Their results again showed that the fortified products were acceptable to consumers. However, our recent studies showed that fortification of fermented milk product with a mixture of fish oil and marine PL did not provide a better oxidative stability than fortification with only fish oil ( $\mathrm{Lu}$ et al., 2013b). Incorporation of neat/pre-emulsified marine PL into fermented milk system increased lipid oxidation in fortified products. This unexpected result is probably due to the initial quality of current marine PL that are available in the market for food application. 


\section{ACCEPTED MANUSCRIPT}

There are several precautions that food manufacturers must beware of in producing marine PL functional foods: a) marine PL incorporation level need to be evaluated on product basis as marine PL might behave differently in different food systems. For instance, incorporation of krill oil into surimi based seafood products did not adversely affect the sensory property of the fortified products, whereas this was not the case for fermented milk product despite the very low incorporation level of marine PL. It is easier for consumers to accept the fishy flavor in surimi based seafood products than in fermented milk system. Therefore, addition of other flavors/fruits such as strawberries may be necessary to mask the fishy flavor in fermented milk system, b) the quality of current marine PL need to be improved prior to their use for food fortification, c) stabilization of marine PL in both emulsion and food systems with additional antioxidants or metal inactivators such as butylated hydroxyanisole (BHA), butylated hydroxytoluene (BHT), ascorbyl palmitate, ethylenediaminetetraacetic acid (EDTA), astaxanthin and $\alpha$-tocopherol. Antioxidant such as $\alpha$-tocopherol might be a good choice to improve the oxidative stability of marine PL fortified foods as previously mentioned (Lu et al., 2012c).

\section{CONCLUSION AND FUTURE PROSPECTS}

Overall, marine PL have high oxidative stability, but as demonstrated in this review the oxidative stability of marine PL is influenced by the quality, source, chemical composition of marine PL and also the degree of non-enzymatic browning reactions in marine PL. In general, the nonenzymatic browning reactions in marine PL are influenced by the marine PL manufacturing processes such as the temperature and conditions of marine PL extraction. In order to further 


\section{ACCEPTED MANUSCRIPT}

investigate lipid oxidation and also the mechanisms of non-enzymatic browning reactions in marine PL, more studies are required in the future to isolate, purify and identify the molecular structures of a) pyrroles, b) oxypolymers and c) the tertiary lipid oxidation products generated in marine PL. In addition, the use of marine PL for food applications is a new area in food industry. Therefore, studies are required in the future to improve the oxidative stability of marine PL in real food systems. For instance, a) the use of appropriate level of marine PL for food fortification should be evaluated on a product basis as marine PL behave differently in different food systems, b) stabilization of marine PL in food systems with addition of antioxidants should be further investigated.

\section{ACKNOWLEDGMENTS}

The authors wish to acknowledge the financial support from Project Healthy Growth at Øresund Food Network (ØRN). 


\title{
ACCEPTED MANUSCRIPT
}

\section{REFERENCES}

Adams, A., Kitryte, V., Venskutonis, R., and Kimpe, N. D. (2009). Formation and characterization of melanoidin like polycondensation products from amino acids and lipid oxidation products. Food Chem. 115: 904-911.

Adams, A., Bouckaert, C., Lancker, F. V., Meulenaer, B. D., and Kimpe, N. D. (2011a). Amino acid catalysis of alkylfuran formation from lipid oxidation derived $\alpha, \beta$-unsaturated aldehydes. $J$. Agric Food Chem. 59: 11058-11062.

\begin{abstract}
Adams, A., Kitryte, V., Venskutonis, R., and Kimpe, N. D. (2011b). Model studies on the pattern of volatiles generated in mixtures of amino acids, lipid oxidation derived aldehydes and glucose. J. Agric Food Chem. 59: 1449-1456.
\end{abstract}

Adams, A., Polizzi, V., Boekel, M. V., and Kimpe, N. D. (2008). Formation of pyrazine and a novel pyrrole in Maillard model systems of 1,3-dihydroacetone and 2-oxopropanal. J. Agric Food Chem. 56: 2147-21531.

Ahmad, I., Alaiz, M., Hidalgo, F. J., and Zamora, R. (1998). Effect of oxidized lipid/amino acid reaction products on the antioxidative activity of common antioxidants. J. Agric Food Chem. 46: $3768-3771$. 


\section{ACCEPTED MANUSCRIPT}

Aidos, I., Jacobsen, C., Jensen, B., Luten, J. B., Padt, A. V. D., and Boom, R. M. (2002). Volatile oxidation products formed in crude herring oil under accelerated oxidative conditions. Eur. Food Res. Technol. 104: 808-818.

Alaiz, M., Hidalgo, F. J., and Zamora, R. (1995a). Antioxidative activity of (E)-2-octenal/amino acids reaction products. J. Agric Food Chem. 43: 795-800.

Alaiz, M., Hidalgo, F. J., and Zamora, R. (1995b). Natural antioxidants produced in oxidized lipid/amino acid browning reactions. J. Am. Oil Chem. Soc. 72: 1571-1575.

Anese, M., and Nicoli, M. C. (2003). Antioxidant properties of ready-to drink coffee brews. $J$. Agric Food Chem. 51: 942-946.

Applegate, K. R., and Glomset, J. A. (1986). Computer-Based Modeling of the Conformation and Packing Properties of Docosahexaenoic Acid. J. Lipid Res. 27: 658-680.

Baek, H. H., and Cadwallader, K. R. C. (1996). Volatile compounds in flavour concentrates produced from crayfish processing by products with and without protease treatment. J. Agric Food Chem. 44: 3262-3267.

Bandarra, N. M., Campos, R. M., Batista, I., Nunes, M. L., and Empis, J. M. (1999). Antioxidant synergy of alpha-tocopherol and phospholipids. J. Am. Oil Chem. Soc. 76: 905-913. 


\section{ACCEPTED MANUSCRIPT}

Belhaj, N., Arab-Tehrany, E., and Linder, M. (2010). Oxidative kinetics of salmon oil in bulk and in nanoemulsion'stabilized by marine lecithin. Process Biochem. 45: 187-195.

Boyd, L. C., Nwosu, V. C., Young, C. L., and MacMillian, L. (1998). Monitoring lipid oxidation and antioxidant effects of phospholipids by headspace gas chromatographic analyses of rancimat trapped volatiles. J. Food Lipids 5: 269-282.

Budzinski, E., Bykowski, P., and Dutkiewicz, D. (1985). FAO fisheries technical paper 268.

Cansell, M., Moussaoui, N., and Lefrancois, C. (2001). Stability of marine lipid basedliposomes under acid conditions. Influence of xanthan gum. J. Liposome Res. 11: 229-242.

Cercaci, L., Rodriguez-Estrada, M. T., Lercker, G., and Decker, E. A. (2007). Phytosterol oxidation in oil-in-water emulsions and bulk oil. Food Chem. 102: 161-167.

Chee, C. P., Roberts, R. F., and Coupland, J. N. (2006). Effect of temperature, time, medium form and casein on lipid oxidation of polyunsaturated fatty acids in algae oil. Milchwissenschaft. 61: $142-145$. 


\section{ACCEPTED MANUSCRIPT}

Chen, H. M., Muramoto, K., Yamauchi, F., and Nokihara, K. (1996). Antioxidant activity of designed peptides base on the antioxidative peptide isolated from digests of a soybean protein. $J$. Agric Food Chem., 44: 2619-2623.

Chung, H. Y., Yung I. K. S., and Kim J. S. (2001). Comparison of volatile components in dried scallops (Chlamys farreri and Patinopecten yessoensis) prepared by boiling and steaming methods. J. Agric Food Chem. 49: 192-202.

Chung, H. Y., Yung, I. K. S., Ma, W. C. J. and Kim, J. S. (2002). Analysis of volatile components in frozen and dried scallops (Patinopecten yessoensis) by gas chromatography/mass spectrometry. Food Res. Int. 35: 43-53.

Cho, S. Y., Joo, D. S., Choi, H. G., Nara, E., and Miyashita, K. (2001). Oxidative stability of lipids from squid tissues. Fish. Sci. 67: 738-743.

Cros, S., Lignot, B., Bourseau, P., Jaouen, P., and Prost, C. (2005). Desalination of mussel cooking juices by electrodialysis: effect on the aroma profile. J. Food Eng. 69: 425-436.

Dobarganes, M. C., and G. Marquez-Ruiz. (2007). Formation and analysis of oxidized monomeric, dimeric and higher oligomeric triglycerides. In: Deep frying: Chemistry, Nutrition and Practical Applications, pp. 87-110. Erickson, M.D., Ed., AOCS Press, Champaign, IL. 


\section{ACCEPTED MANUSCRIPT}

Dunford, H. B. (1987). Free radicals in iron containing systems. Free Radical Biol. Med. 3: 405421.

Farmer, L. J., and Mottram, D. S. (1990). Interaction of lipid in the Maillard reaction between cysteine and ribose: the effect of a triglyceride and three phospholipids on the volatile products $J$. Sci. Food Agric. 53: 505-525.

Finean, J. B. (1990). Interaction Between Cholesterol and Phospholipid in Hydrated Bilayers. Chem. Phys. Lipids 54: 147-156.

Fiorentini, D., Landi, L., Barzanti, V., and Cabrini, L. (1989). Buffers can modulate the effect of sonication on egg lecithin liposomes. Free Radical Res Com. 6: 243-250

Flores, M., Spanier, A. M., and Toldra, F. (1998). Flavour analysis of dry-cured ham. In: Flavour of meat and meat products and seafoods, pp. 320-341. Shahidi, F. Ed., Blackie Academic and Professional, London, UK.

Frankel, E. N. (2005). Lipid Oxidation. Bridgwater, England: The Oily Press.

Garcia, E., Gutierrez, S., Nolasco, H., Carreon, L., and Arjona, O. (2006). Lipid composition of shark liver oil: effects of emulsifying and microencapsulation processes. Eur. Food Res. Technol. 222: 697-701. 


\section{ACCEPTED MANUSCRIPT}

Giogios, I., Grigorakis, K., Nengas, I., Papasolomontos, S., Papaioannou, N., and Alexis, M. N. (2008). Fatty acid composition and volatile compounds of selected marine oils and meals. J. Sci. Food Agric. 89: 88-100.

Gritt M., Zuidam N. J., Underberg, W. J. M., and Crommelin, D. J. A. (1993). Hydrolysis of partially saturated egg phosphatidylcholine in aqueous liposome dispersions and the effect of cholesterol incorporation in hydrolysis kinetics. J. Pharm. Pharmacol. 45: 490-495.

Guo, H., Kouzuma, Y., and Yonekura, M. (2009). Structures and properties of antioxidative peptides derive from royal jelly protein. Food Chem. 113: 238-245.

Halliwell, B., and Gutteridge, J. (1990). Role of free radicals and catalytic metal ions in human disease: an overview. Meth. Enzymol. 186: 1-85.

Hartvigsen, K., Lund, P., Hansen, L. F., and Hølmer, G. (2000). Dynamic headspace gas chromatography/mass spectrometry characterization of volatiles produced in fish oil enriched mayonnaise during storage. J. Agric Food Chem. 48: 4858-4867.

Hidalgo, F. J., Mercedes leoan, M., and Zamora, R. (2006). Antioxidative activity of amino phospholipids and phospholipid/amino acid mixtures in edible oils as determined by the Rancimat method. J. Agric Food Chem. 54: 5461-5467. 


\section{ACCEPTED MANUSCRIPT}

Hidalgo, F. J., Mercedes leoan, M., Nogales, F., and Zamora, R. (2007). Effect of Tocopherols in the Antioxidative Activity of Oxidized Lipid-Amine Reaction Products. J. Agric Food Chem., 55: 4436-4442.

Hidalgo, F. J., Nogales, F., and Zamora, R. (2003). Effect of the pyrrole polymerization mechanism on the antioxidative activity of nonenzymatic browning reactions. J. Agric Food Chem. 51: 5703-5708.

Hidalgo, F. J., Nogales, F. and Zamora, R. (2005a). Nonenymatic Browning, Fluorescence development, and formation of pyrrole derivatives in phosphatidylethanolamine/Ribose/ Lysine model systems. J. Food Sci. 70: 387-391.

Hidalgo, F. J., Nogales, F., and Zamora, R. (2005b). Changes produced in the antioxidative activity of phospholipids as a consequence of their oxidation. J. Agric Food Chem. 53: 659-662.

Hidalgo, F. J. and Zamora, R. (2004). Strecker -type degradation produced by the lipid oxidation products 4, 5-epoxy-2-alkenals. J. Agric Food Chem. 52: 7126-7131.

Hidalgo, F. J. and Zamora, R. (2005). Interplay between the Maillard reaction and lipid peroxidation in biochemical systems, .Ann. N. Y. Acad. Sci. 1043: 319-326. 


\section{ACCEPTED MANUSCRIPT}

Hwang, H. I., Hartman, T. G., Rosen, R. T. and Ho, C. T. (1993). Formation of pyrazine from maillard reaction of glucose and glutamine-amine-15N. J. Agric Food Chem. 41: 2112-2115.

Ierna, M., Kerr, A., Scales, H., Berge, K., and Griinari, M. (2010). Supplementation of diet with krill oil protects against experimental rheumatoid arthritis. BMC Musculoskelet. Dis.11.

Karahadian, C., and Lindsay, R. C. (1989). Evaluation of compounds contributing characterizing fishy flavours in fish oil. J. Am. Oil Chem. Soc. 66: 953-960.

Kassis, N. M., Beamer, S. K., Matak, K. E., Tou, J. C., and Jaczynski, J. (2010). Nutritonal composition of novel nutraceutical egg products developed with omega-3-rich oils. LWT- Food Sci. Technol. 43: 1204-1212.

Kassis, N. M., Gigliotti, J. C., Beamer, S. K., Tou, J. C., and Jaczynski, J. (2011). Characterization of lipids and antioxidant capacity of novel nutraceutical egg products developed with omega-3-rich oils. J. Sci. Food Agric. 92: 66-73.

Khayat, A., and Schwall, D. (1983). Lipid oxidation in seafood. Food Technol. 37: 130-1400.

Kim, Y. S., Hartman, T. G., and Ho, C. T. (1996). Formation of 2-pentypyridine from the thermal interaction of amino acids and 2, 4-decadienal. J. Agric Food Chem. 44: 3906-3908. 


\section{ACCEPTED MANUSCRIPT}

Kim, Y. S., and Ho, C. T. C. (1998). Formation of pentypyridines in an oil medium. J. Agric Food Chem. 46: 644-647.

Kim, I. H., Kim, C. J., and Kim, D. H. (1999). Physicochemical properties of methyl linoleate oxidized at various temperatures. Korean J. Food Sci. Technol. 31: 600-605.

King, M. F., Boyd, L. C., and Sheldon, B. W. (1992a). Effects of Phospholipids on Lipid Oxidation of A Salmon Oil Model System. J. Am. Oil Chem. Soc. 69: 237-242.

King, M. F., Boyd, L. C., and Sheldon, B. W. (1992b). Antioxidant Properties of Individual Phospholipids in A Salmon Oil Model System. J. Am. Oil Chem. Soc. 69: 545-551.

Kubota K., Nakamoto, a., Moriguchi, M., Kobayashi, A., and Ishii, H. (1991). Formation of pyrrolidino[1, 2-e]-4H-2, 4-dimethy-1, 3, 5-dithiazine in the volatiles of boiled short necked clam, clam and corbicula. J. Agric Food Chem. 39: 1127-1130.

Le Grandois, J., Marchioni, E., Zhao, M. J., Giuffrida, F., Ennahar, S., and Bindler, F. (2009) Investigation of Natural Phosphatidylcholine Sources: Separation and Identification by Liquid Chromatography-Electrospray Ionization-Tandem Mass Spectrometry (LC-ESI-MS2) of Molecular Species. J. Agric Food Chem. 57: 6014-6020. 


\section{ACCEPTED MANUSCRIPT}

Linder, M., and Ackman, R. G. (2002). Volatile compounds recovered by Solid Phase Microextraction from fresh adductor muscle and total lipids of sea scallop (Placopecten magellanicus) from Georges Bank (Nova Scotia). J. Food Sci. 67: 2032-2037.

Loidl-Stahlhofen, A., and Spiteller, G. (1994). $\alpha$-hydroxyaldehydes, products of lipid peroxidation. Biochim. Biophys. Acta. 1211: 156-160.

Lu, F. S. H., Bruheim, I., Haugsgjerd, B. O., and Jacobsen, C. (2014). Effect of temperature towards lipid oxidation and non-enzymatic browning reactions in krill oil upon storage. Food Chem. 157: 398-407.

Lu, F. S. H., Nielsen, N, S., Heinrich, M. T., and Jacobsen, C. (2011). Oxidative stability of marine phospholipids in the liposomal form and their applications: A review. Lipids, 46: 3-23.

Lu, F. S. H., Nielsen, N, S., Baron, C. P., Jensen, L. H. S., and Jacobsen, C. (2012a). Physicochemical properties of marine phospholipid emulsions. J. Am. Oil Chem. Soc. 89: 2011-2024.

Lu, F. S. H., Nielsen, N, S., Baron, C. P., and Jacobsen, C. (2012b). Oxidative degradation and non-enzymatic browning due to the interaction between oxidized lipids and primary amine groups in different marine phospholipid emulsions. Food Chem. 135: 2887-2896. 


\section{ACCEPTED MANUSCRIPT}

Lu, F. S. H., Nielsen, N, S., Baron, C. P., Diehl, B. W. K., and Jacobsen, C. (2012c). Oxidative stability of emulsions prepared from purified marine phospholipid and the role of $\alpha$-tocopherol. J. Agric Food Chem. 60: 12388-12396.

Lu, F. S. H., Nielsen, N, S., Baron, C. P., Diehl, B. W. K., and Jacobsen, C. (2013a). Impact of primary amine group from aminophospholipids and amino acids on marine phospholipid stability: Non-enzymatic browning and lipid oxidation. Food Chem. 141: 879-888.

Lu, F. S. H., Thomsen, B. R., Hyldig, G., Green-Petersen, D. M. B., Nielsen, N. S., Baron, C. P., and Jacobsen, C. (2013b). Oxidative stability and sensory attributes of fermented milk product fortified with a neat or pre-emulsified mixture of fish oil and marine phospholipids. J. Am. Oil Chem. Soc. 90: 1673-1683.

McClements, D. J., and Decker, E. A. (2000). Lipid oxidation in oil-in water emulsions: Impact of molecular environment on chemical reactions in heterogeneous food systems. J. Food Sci. 65: $1271-1282$.

Mei, L. Y., Decker, E. A., and McClements, D. J. (1998a). Evidence of iron association with emulsion droplets and its impact on lipid oxidation. J. Agric Food Chem. 46: 5072-5077.

Mei, L. Y., McClements, D. J., Wu, J., and Decker, E. A. (1998b). Iron catalyzed lipid oxidation in emulsion as affected by surfactant, pH, NaCl. Food Chem. 61: 307-312. 


\section{ACCEPTED MANUSCRIPT}

Methven, L., Tsoukka, M., Concha, M. J. O., Pakker, J. K., and Mottram, D. S. (2007). Influence of sulfur amino acids on the volatile and nonvolatile components of cooked salmon (Salmo salar). J. Agric Food Chem. 55: 1427-1436.

Minotti, G., and Aust, S. (1989). The role of iron in oxygen radical mediated lipid peroxidation. Chem-Biol Interact. 71: 1-19.

Miyashita, K., Nara, E., and Ota, T. (1994). Comparative-Study on the Oxidative Stability of Phosphatidylcholines from Salmon Egg and Soybean in An Aqueous-Solution. Biosci. Biotechnol. Biochem. 58: 1772-1775.

Mlakar, A., and Spiteller, G. (1994). Reinvestigation of lipid peroxidation of linolenic acid, Biochim. Biophys. Acta. 1214: 270-280.

Morita, K., Kubota, K., and Aishima, T. (2001). Sensory characteristics and volatile components in aromas of boiled prawns prepared according to experimental designs. Food Res. Int. 34: 473481.

Moriya, H., Kuniminato, T., Hosokawa, M., Fukunaga, K., Nishiyama, T., and Miyashita, K. (2007). Oxidative stability of salmon and herring roe lipids and their dietary effect on plasma cholesterol levels of rats. Fish. Sci. 73: 668-674. 


\section{ACCEPTED MANUSCRIPT}

Mozuraityte, R., Rustad, T., and Storro, I. (2006a). Pro-oxidant activity of $\mathrm{Fe}^{2+}$ in oxidation of cod phospholipids in liposomes. Eur. J. Lipid Sci. Technol. 108: 218-226.

Mozuraityte, R., Rustad, T., and Storro, I. (2006b). Oxidation of cod phospholipids in liposomes: Effects of salts, pH and zeta potential. Eur. J. Lipid Sci. Technol. 108: 944-950.

Mozuraityte, R., Rustad, T., and Storro, I. (2008). The role of iron in peroxidation of polyunsaturated fatty acids in liposomes. J. Agric Food Chem. 56: 537-543.

Nacka, F., Cansell, M., Meleard, P., and Combe, N. (2001a). Incorporation of alpha tocopherol in marine lipid-based liposomes: in vitro and in vivo studies. Lipids, 36: 1313-1320.

Nacka, F., Cansell, M., Gouygou, J. P., Gerbeaud, C., Meleard, P., and Entressangles, B. (2001b). Physical and chemical stability of marine lipid-based liposomes under acid conditions. Colloids Surf B. 20: 257-266.

Nara, E., Miyashita, K., and Ota, T. (1997). Oxidative stability of liposomes prepared from soybean PC, chicken egg PC, and salmon egg PC. Biosci. Biotechnol. Biochem. 61: 1736-1738.

Nara, E., Miyashita, K., Ota, T., and Nadachi, Y. (1998). The oxidative stabilities of polyunsaturated fatty acids in salmon egg phosphatidylcholine liposomes. Fish. Sci. 64: 282-286. 


\section{ACCEPTED MANUSCRIPT}

Negroni, M., D’Agostina, A., and Arnoldi, A. (2001). Effects of olive, canola, and sunflower oils on the formation of volatiles from the Maillard reaction of lysine with xylose and glucose. $J$. Agric Food Chem. 41: 227-230.

Peng, J. L., Larondelle, Y., Pham, D., Ackman, R. G., and Rollin, X. (2003). Polyunsaturated fatty acid profiles of whole body phospholipids and triacylglycerols in anadromous and landlocked Atlantic salmon (Salmo salar L.) fry. Comp Biochem Phys B. 134: 335-348.

Pietrowski, B. N., Tahergorabi, R., Matak, K. E., Tou, J. C., and Jaczynski, J. (2011). Chemical properties of surimi seafood nutrified with $\omega-3$ rich oils. Food Chem. 129: 912-919.

Pokorny, J., and Sakurai, H. (2002). Role of oxidized lipids in nonenzymatic browning reactions. Int. Congr. Ser. 1245: 373-374.

Reische, D. W., Lillard, D. A., and Eitenmiller, R. R. (2008). Antioxidants. In: Food lipids: Chemistry, Nutrition and Biotechnology. Pp.409-434. Akoh, C. C., and Min, D. B., Eds., CRC Press, Boca Raton, FL.

Rizzi, G. P. (2008). The Strecker degradation of amino acids: Newer avenues flavor formation. Food Rev. Int. 24: 416-435. 


\section{ACCEPTED MANUSCRIPT}

Sedoski, H. D., Beamer, S. K., Jaczynski, J., Partington, S., and Matak, K. E. (2012). Sensory evaluation and quality indicators of nutritionally enhanced egg products with $\omega-3$ rich oils. $L W T$ Food Sci. Technol. 47: 459-464.

Shibamoto, T., Akiyama, T., Sakaguchi, M., Enomoto, Y., and Masuda, H. (1979). A study of pyrazine formation. J. Agric Food Chem., 27: 1027-1031.

Sørensen, A. D. M., Nielsen, N. S., Hyldig, G., and Jacobsen, C. (2010a). The influence of emulsifier type on lipid oxidation in fish oil enriched light mayonnaise. Eur. Food Res. Technol. 112: $476-487$.

Sørensen, A. D. M., Nielsen, N. S., and Jacobsen, C. (2010b). Oxidative stability of fish oil enriched mayonnaise based salads. Eur. Food Res. Technol. 112: 476-487

Tadolini, B., and Hakim, G. (1996). The mechanism of iron (III) stimulation of lipid peroxidation. Free Radical Res. 25: 221-227.

Thanonkaew A., Benjakul S., Visessanguan W., and Decker, E. A. (2005). Lipid oxidation in microsomal fraction of squid muscle (Loligo peali). J. Food Sci. 70: 478-482.

Thanonkaew A., Benjakul S., and Visessanguan W. (2006a). Chemical composition and thermal property of cuttlefish (Sepia pharaonis) muscle. J. Food Compos. Anal. 19: 127-133. 


\section{ACCEPTED MANUSCRIPT}

Thanonkaew A., Benjakul S., Visessanguan W., and Decker, E. A. (2006b). Development of yellow pigmentation in squid (Loligo peali) as a result of lipid oxidation. J. Agric Food Chem. 54: $956-962$.

Thanonkaew A., Benjakul S., Visessanguan W., and Decker, E. A. (2007). Yellow discoloration of the liposome system of cuttlefish (Sepia pharaonis) as influenced by lipid oxidation. Food Chem. 102: 219-2240.

Thomsen, B. R., Haugsgjerd, B. O., Griinari, M., Lu, H. F. S., Bruheim, I., Vogt, G., Oterhals, A. and Jacobsen, C. (2013). Investigation of oxidative degradation and non-enzymatic browning reactions in krill and fish oils. Eur. J. Lipid Sci. Technol. 115: 1357-1366.

Tilseth, S., and Hostmark, O. (2009). Method for making krill meal. US20090061067 A1.

Tompkins, C., and Perkins, E. G. (2000). Frying performance of low linolenic acid soybean oil. J. Am. Oil Chem. Soc. 77: 223-229.

Uematsu, T., Parkanyiova, L., Endo, T., Matsuyama, C., Yano, T., Mitsuyoshi, M., Sakurai, H., and Pokorny, J. (2002). Effect of the unsaturation degree on browning reactions of peanut oil and other edible oils with proteins under storage and frying conditions. International Int. Congr. Ser. 1245: 445-446. 


\section{ACCEPTED MANUSCRIPT}

Varlet, V., and Fernandez, X. (2010). Review: Sulfur containing volatile compounds in seafood: occurrence, odorant properties and mechanisms of formation. Food Sci. Technol. Int. 16: 463503.

Venkateshwarlu, G., Let, M. B., Meyer, A. S., and Jacobsen, C. (2004). Chemical and olfactometric characterization of volatile flavour compounds in a fish oil enriched milk emulsion. J. Agric Food Chem. 52: 311-317.

Ventanas, S., Estevez, M., and Delgado, C. L. (2007). Phospholipid oxidation, non-enzymatic browning development and volatile compounds generation in model systems containing liposomes from porcine Longissimus dorsi and selected amino acids. Eur. Food Res. Technol. 225: $665-675$.

Waraho, T., McClement, D. J., and Decker, E. A. (2011). Mechanisms of lipid oxidation in food dispersions. Trends in Food Sci. and Tech. 22: 3-13.

Weng, X. C., and Gordon, M. H. (1993). Antioxidant Synergy Between Phosphatidyl Ethanolamine and Alpha-Tocopherylquinone, Food Chem. 48: 165-168. 


\section{ACCEPTED MANUSCRIPT}

Wijendran, V., Huang, M. C., Diau, G. Y., Boehm, G., Nathanielsz, P. W., and Brenna, J. T. (2002). Efficacy of dietary arachidonic acid provided as triglyceride or phospholipid as substrates for brain arachidonic acid accretion in baboon neonates. Pediatr. Res. 51: 265-272.

Yu, H. Z., and Chen, S. S. (2010). Identification of characteristic aroma-active compounds in steamed mangrove crab (Scylla serrata). Food Res. Int. 43: 2081-2086.

Zamora, R., Alaiz, M., and Hidalgo, F. J. (2000). Contribution of pyrrole formation and polymerization to the nonenzymatic browning produced by amino-carbonyl reactions. J. Agric Food Chem. 48: 3152-3158.

Zamora, R., Gallardo, E., and Hidalgo, F. J. (2007). Strecker degradation of phenylalanine initiated by 2, 4-decadienal or methyl 13-oxooctadeca-9, 11-dienoate in model systems. J. Agric Food Chem. 55: 1308-1314.

Zamora, R., and Hidalgo, F. J. (1994). Modification of lysine amino groups by the lipid peroxidation product 4, 5(E)-epoxy-2(E)-heptenal. Lipids, 29: 243-249.

Zamora, R., and Hidalgo, F. J. (1995). Linoleic acid oxidation in the presence of amino compounds produces pyrroles by carbonyl amine reactions. Biochim. Biophys. Acta. 1258: 319327. 


\section{ACCEPTED MANUSCRIPT}

Zamora, R., and Hidalgo, F. J. (2005). Coordinate contribution of lipid oxidation and Maillard reaction to the nonenzymatic food browning. Crit Rev Food Sci Nutr 45: 49-59.

Zamora, R., and Hidalgo, F. J. (2011). The Maillard reaction and lipid oxidation. Lipid Technol. 23: $59-62$.

Zamora, R., Nogales, F., and Hidalgo, F. J. (2005). Phospholipid oxidation and nonenzymatic browning development in phosphatidylethanolamine/ ribose/lysine model systems. Eur. Food Res. Technol. 220: 459-465.

Zamora, R., Olmo, C., Navarro, J. L., and Hidalgo, F. J. (2004). Contribution of phospholipid pyrrolization to the color reversion produced during deodorization of poorly degummed vegetable oils. J. Agric Food Chem. 52: 4166-4171. 


\section{ACCEPTED MANUSCRIPT}

Table 1 Some of the selected n-3 LC PUFA derived secondary volatiles and their odours.

\begin{tabular}{|c|c|c|}
\hline Volatiles & Odour description & References* \\
\hline Propanal & Sharp, irritating, plastic & $\mathrm{c}-\mathrm{e}$ \\
\hline (Z)-4-Heptenal & Creamy, stale, burnt, fishy & $a, b, d-f$ \\
\hline$(E, Z)-2,4$-Heptadienal & burnt, fishy, fatty & $\mathrm{a}-\mathrm{e}$ \\
\hline$(E, E)$-2,4-Heptadienal & Fishy, rancid, green & $\mathrm{a}-\mathrm{c}, \mathrm{e}, \mathrm{f}$ \\
\hline$(E, Z)$-2,6-Nonadienal & fresh cucumber, green, melon & $a-f$ \\
\hline$(E, E)-2,6$-Nonadienal & deep fried, fatty, cucumber, & $\mathrm{b}$ \\
\hline 1-penten-3-one & pungent, fishy, plastic & $b-d, f$ \\
\hline (E)-2-Hexenal & green & $\mathrm{c}, \mathrm{d}, \mathrm{f}$ \\
\hline 1-octen-3-one & mushroom & $\mathrm{b}, \mathrm{c}$ \\
\hline 1,5-octadien-3-one & metallic & $\mathrm{a}-\mathrm{c}$ \\
\hline \multicolumn{3}{|c|}{ The information is adapted from other studies from literature: a) Karahadian et al. (1989), b) } \\
\hline Hartvigsen et al. (2000 & enkateshwarlu et al. (2004) and & al studies on $n$ \\
\hline
\end{tabular}




\section{ACCEPTED MANUSCRIPT}

Table 2 Some of the selected volatiles from seafood products and model systems containing primary amine group. 


\section{ACCEPTED MANUSCRIPT}

\begin{tabular}{|c|c|c|}
\hline Volatiles & previously reported in products/ derived from amino acids & References* \\
\hline dimethyl sulphide & shrimp, anchovy, oyster/ methonine & $\mathrm{a}, \mathrm{d}$ \\
\hline dimethyl disulphide & scallop, oyster, cooked salmon, crayfish hydrolysates / methonine & $\mathrm{a}, \mathrm{b}, \mathrm{d}, \mathrm{f}-\mathrm{h}, \mathrm{j}, \mathrm{p}, \mathrm{r}-\mathrm{t}$ \\
\hline dimethyl trisulphide & crab, cooked salmon, crayfish hydrolysates / methonine & $\mathrm{c}, \mathrm{d}, \mathrm{f}, \mathrm{i}, \mathrm{j}, \mathrm{p}, \mathrm{s}, \mathrm{t}$ \\
\hline dimethyl sulfoxide & mussel juice, squid, crab, roasted shrimps & $\mathrm{k}, 1$ \\
\hline dimethyl sulfone & scallop, processed shrimps/prawns & $\mathrm{m}, \mathrm{n}$ \\
\hline hydrogen sulphide & boiled clams & o \\
\hline pyridines & scallop, crab, cooked salmon, crayfish hydrolysates & $\mathrm{a}-\mathrm{c}, \mathrm{f}, \mathrm{i}, \mathrm{j}, \mathrm{p}, \mathrm{s}, \mathrm{t}$ \\
\hline 3-methylpyridine & scallop & $\mathrm{a}, \mathrm{b}, \mathrm{s}$ \\
\hline trimethylpyrazine & crab, crayfish hydrolysates & $\mathrm{c}, \mathrm{i}, \mathrm{j}$ \\
\hline 3-ethyl-2,5-diethylpyrazine & & $\mathrm{p}$ \\
\hline 2,3-dimethylpyrazine & shrimp (raw, fermented, cooked), crayfish hydrolysates, & $a, b, j, p$ \\
\hline 2,5-dimethylpyrazine & roasted squid, clam, cooked salmon, crayfish hydrolysates & $b, f, i, j, s$ \\
\hline
\end{tabular}




\section{ACCEPTED MANUSCRIPT}

\begin{tabular}{lll}
\hline 2-methyl-2-pentenal & oyster, anchovy, scallop/ lysine & $\mathrm{a}, \mathrm{b}, \mathrm{e}, \mathrm{h}, \mathrm{i}, \mathrm{p}, \mathrm{r}$ \\
3-methylbutanal & crab, cooked salmon / leucine & $\mathrm{c}, \mathrm{f}-\mathrm{h}, \mathrm{p}-\mathrm{r}, \mathrm{t}$ \\
2-methylbutanal & crab, cooked salmon / leucine & $\mathrm{c}, \mathrm{f}$ - h, p, s, t \\
benzaldehyde & cooked salmon, oyster, shrimp, crayfish hydrolysates & $\mathrm{a}, \mathrm{d}, \mathrm{f}-\mathrm{j}, \mathrm{p}, \mathrm{s}, \mathrm{t}$ \\
2-methyl-2-butenal & dried scallops, cooked salmon, crayfish hydrolysates / lysine & $\mathrm{b}, \mathrm{e}-\mathrm{h}, \mathrm{j}, \mathrm{p}, \mathrm{r}$ \\
2-pentylfuran & dried scallops, cooked salmon, crayfish hydrolysates & $\mathrm{b}, \mathrm{d}, \mathrm{f}-\mathrm{h}, \mathrm{p}, \mathrm{s}$ \\
2-methylpropanal & roasted dried squid, anchovy & $\mathrm{a}, \mathrm{g}, \mathrm{h}, \mathrm{p}$
\end{tabular}

The information of this table is adapted from literature studies: a) fresh adductor muscle and sea scallop (Linder and Ackman, 2002); b) dried scallops (Chung et al., 2001); c) steamed mangrove crab (Yu and Chen, 2010); d) model system containing liposomes and selected amino acids (Ventanas et al., 2007), e) model system containing epoxyalkenals and lysine or albumin (Zamora and Hidalgo, 1994), f) cooked salmon (Methven et al., 2007), g) fish meal (Giogios et al., 2008), h) krill meal (Giogios et al., 2008), i) krill meal and krill oil (Tilseth and Hostmark, 2009), j) crayfish hydrolysates ( Baek and Cadwallader, 1996); k) mussel juice, squid, crab, roasted shrimps (Varlet and Fernandez, 2010); 1) mussel juices (Cros et al., 2005), m) scallop (Chung et al., 2002); n) processed shrimps/prawns (Morita et al., 2001); o) boiled clam (Kubota et al., 1991) 


\section{ACCEPTED MANUSCRIPT}

and several studies on marine PL and krill oil from our laboratory: p) Lu et al. (2012b), q) Lu et al. (2012c), r) Lu et al. (2013a), s) Lu et al. (2014) and t) Thomsen et al. (2013). 


\section{ACCEPTED MANUSCRIPT}

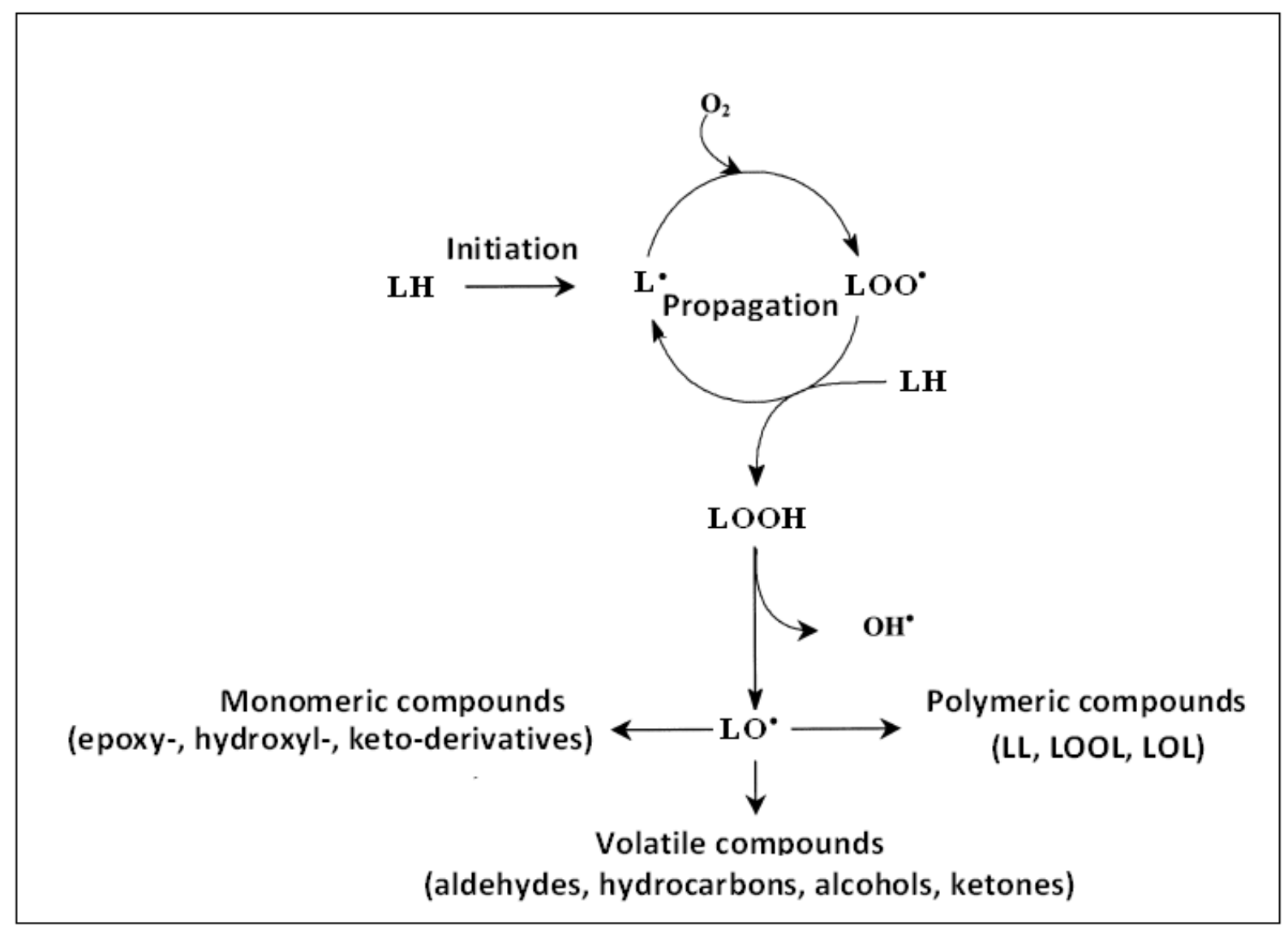

Figure 1 Oxidation mechanisms of polyunsaturated lipids. LH: Unsaturated lipid; L $^{\bullet}$ Lipid alkyl radical; $\mathrm{LO}^{\bullet}$ : Lipid alkoxyl radical; $\mathrm{LOO}^{\bullet}$ : Lipid peroxyl radical; LOOH: Lipid hydroperoxide (Adapted from Frankel, 2005; Dobarganes and Marquez-Ruiz, 2007) 


\section{ACCEPTED MANUSCRIPT}

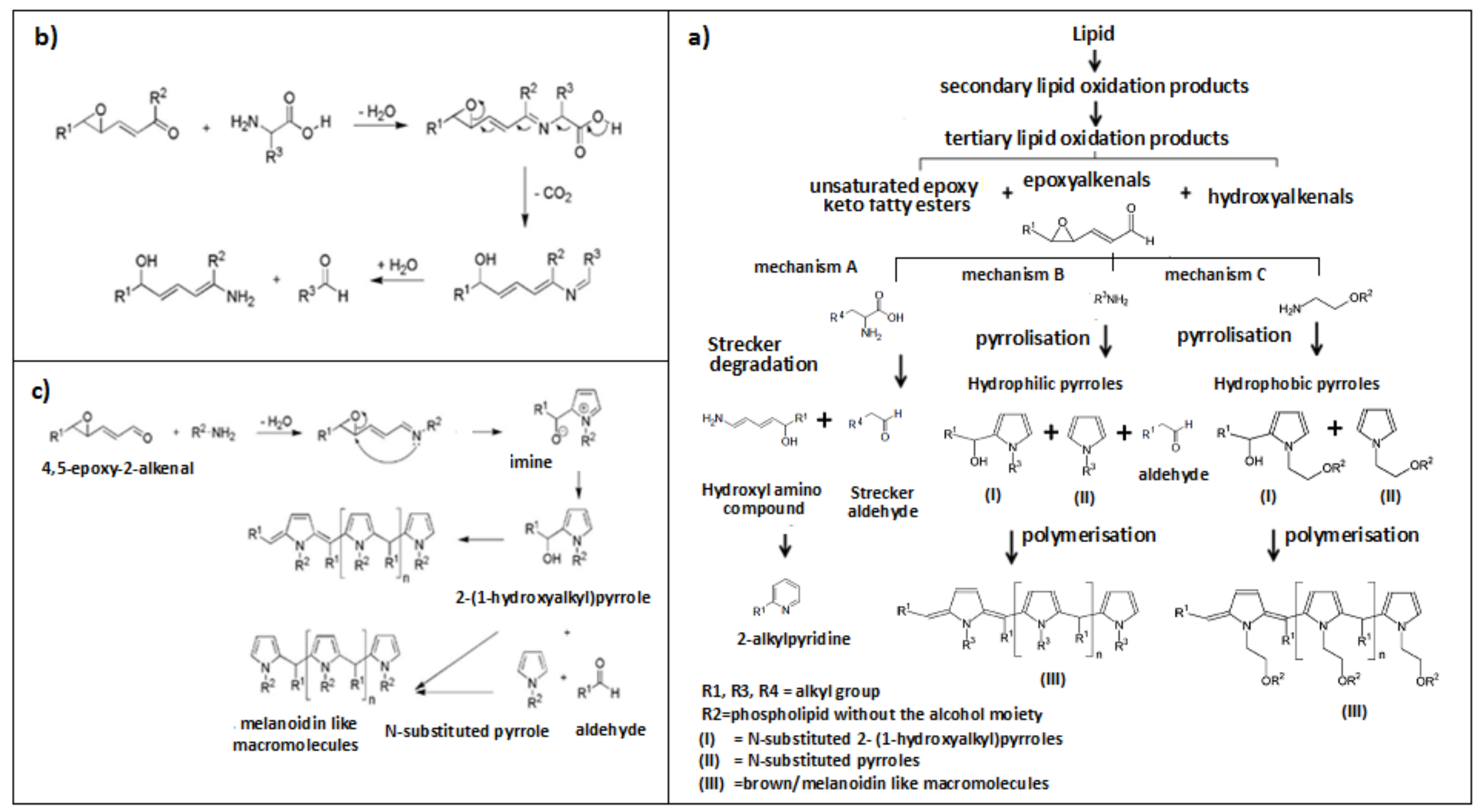

Figure 2: Proposed mechanisms for a) non-enzymatic browning reactions; b) Strecker degradation; c) pyrrolisation in marine

PL. Adapted from Hidalgo and co-workers (Hidalgo et al., 2007; Hidalgo and Zamora, 2004, 2005; Zamora et al., 2007). 


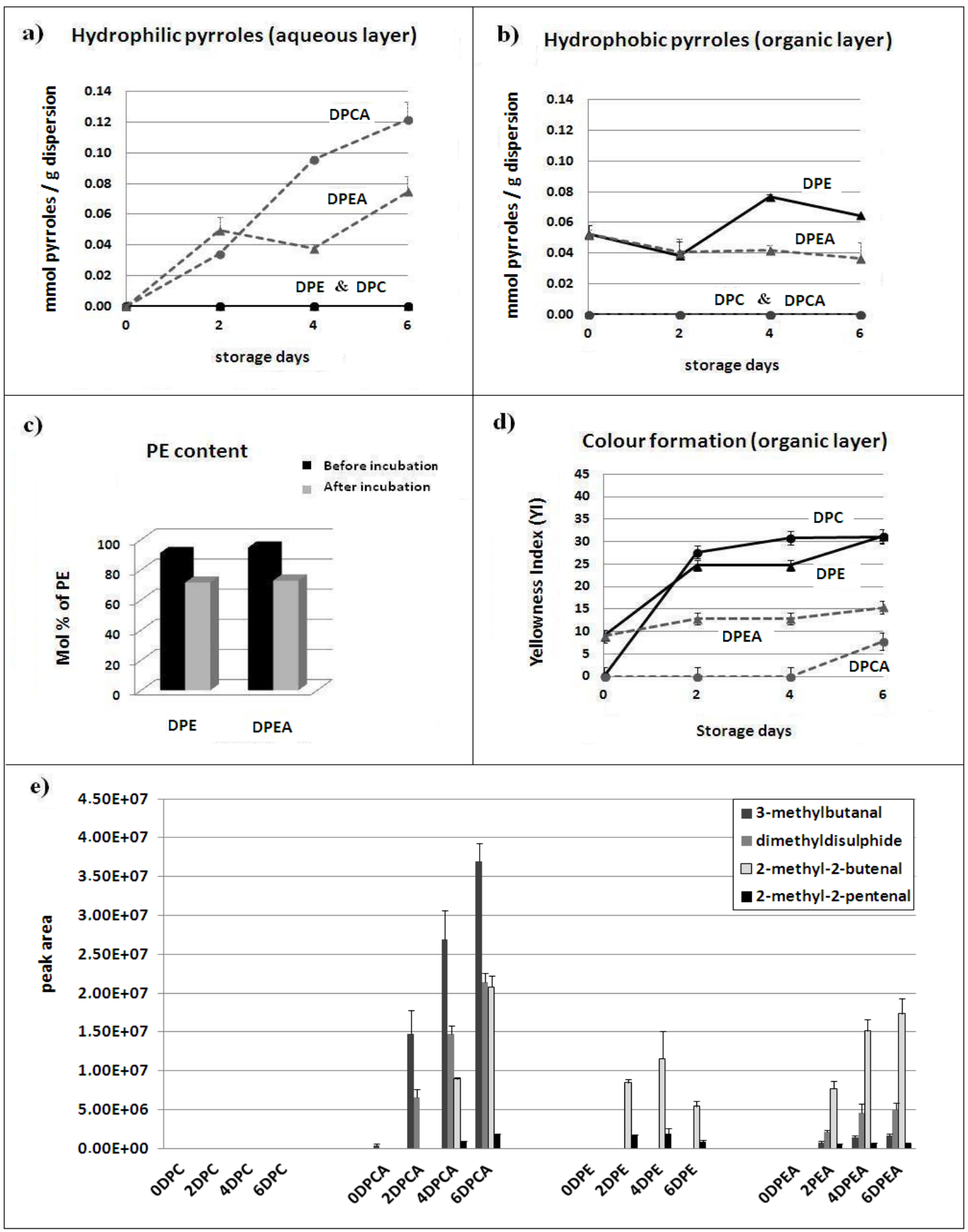




\section{ACCEPTED MANUSCRIPT}

Figure 3 Measurement of hydrophilic pyrroles (a), hydrophobic pyrroles (b) and Strecker derived volatiles (c) in liposomal dispersions over 6 days incubation at $60^{\circ} \mathrm{C}$. DPE and DPC are liposomal dispersions prepared from authentic standards PC and PE (purity > 99\%, contain C16:0 fatty acids at $s n-1$ position and C22:6 fatty acids at $s n-2$ position, purchased from Avanti Polar Lipids). DPEA and DPCA are PE and PC liposomal dispersions added with $100 \mathrm{mg}$ of amino acids, namely leucine, methonine and lysine, respectively. Values are means \pm standard deviation $(n=3)$. Data are taken from Lu et al (2013a). 


\section{ACCEPTED MANUSCRIPT}

a)

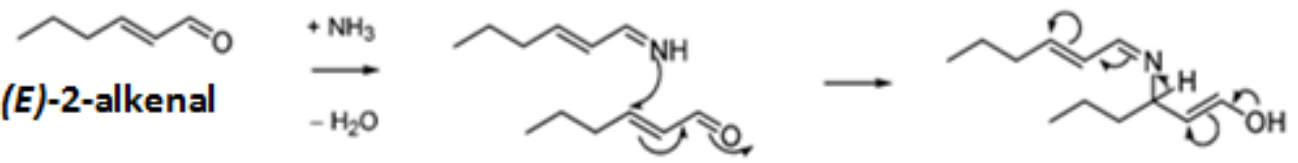

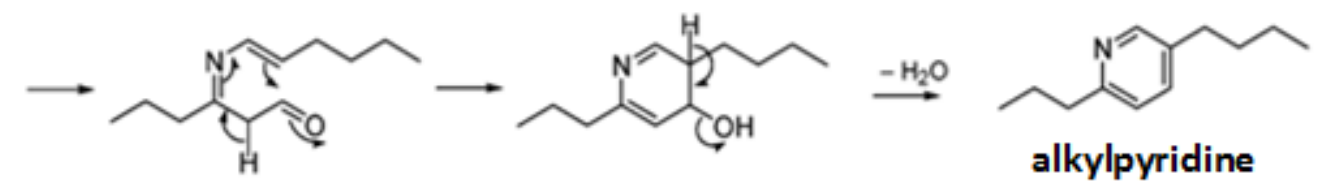

(5-butyl-2-propylpyridine)

b)

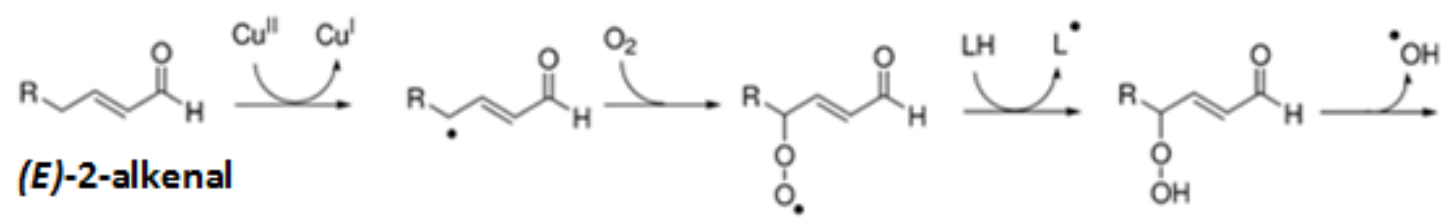

(E)-2-alkenal

O.

4-hydroxy-2-alkenals

2-alkylfuran

c)

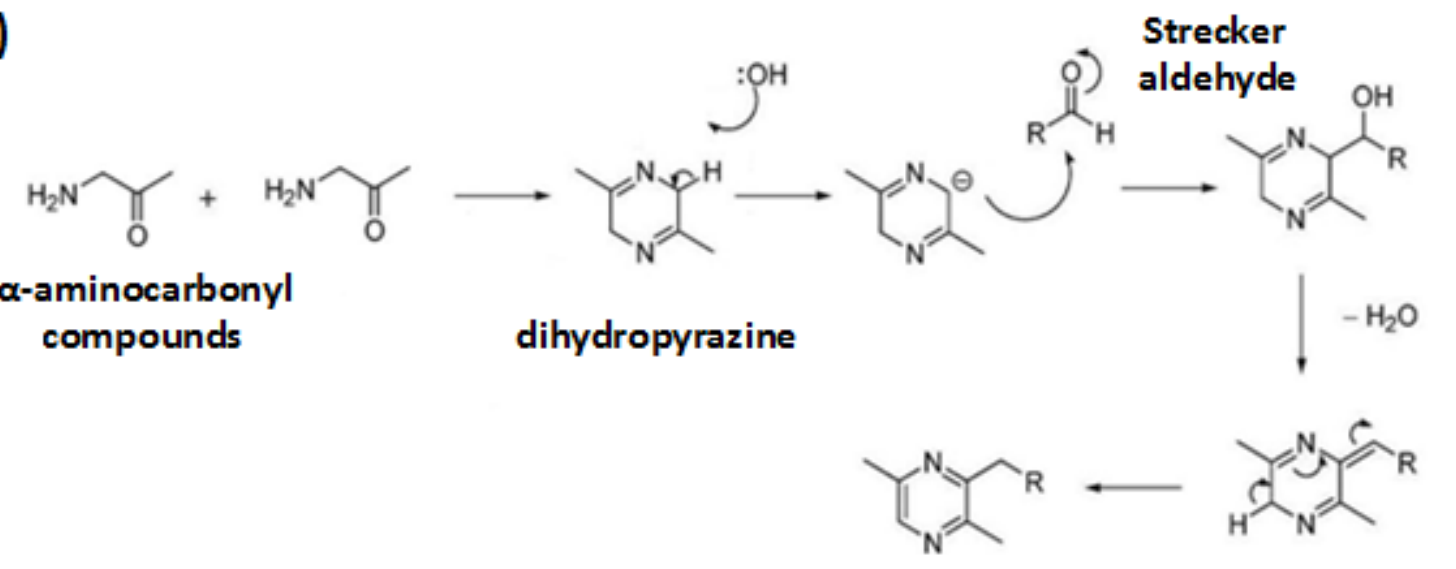

3-alkyl-2,5-dimethylpyrazine 


\section{ACCEPTED MANUSCRIPT}

Figure 4: Proposed mechanisms for formation of a) alkylpyridines and b) alkylfuran from $\alpha, \beta$ unsaturated aldehydes, c) alkylpyrazines from $\alpha$-amino carbonyl compounds (adapted from Adams et al., 2008; 2011a, 2011b). 


\section{ACCEPTED MANUSCRIPT}

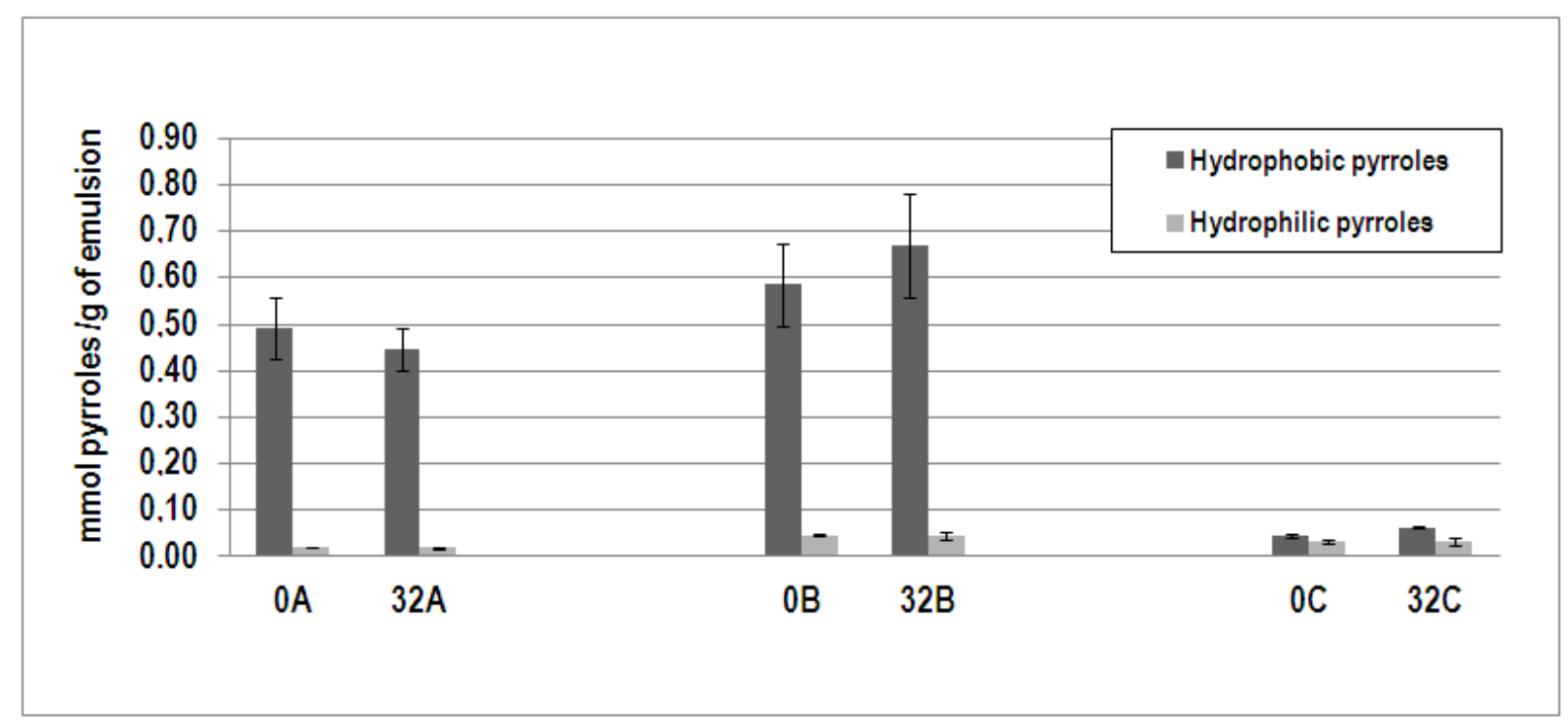

Figure 5: Comparison of hydrophobic pyrroles and hydrophilic pyrroles in three different marine PL emulsions (A, B and C) before (0) and after (32) days storage at $2{ }^{\circ} \mathrm{C}$. Values are mean \pm standard deviation $(n=2)$. Data are taken from Lu et al (2012b). 


\section{ACCEPTED MANUSCRIPT}
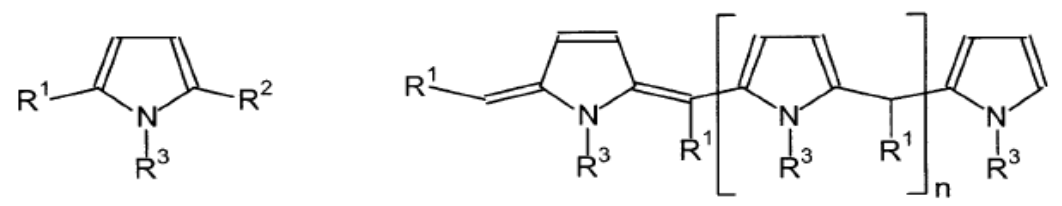

\begin{tabular}{lcccc}
\hline Compound & $\mathrm{n}$ & $\mathrm{R}^{1}$ & $\mathrm{R}^{2}$ & $\mathrm{R}^{3}$ \\
\hline Pyrrole & - & $\mathrm{H}$ & $\mathrm{H}$ & $\mathrm{H}$ \\
1-Methylpyrrole & - & $\mathrm{H}$ & $\mathrm{H}$ & $\mathrm{CH}_{3}$ \\
2,5-Dimethylpyrrole & - & $\mathrm{CH}_{3}$ & $\mathrm{CH}_{3}$ & $\mathrm{H}$ \\
1,3,5-Trimethylpyrrole & - & $\mathrm{CH}_{3}$ & $\mathrm{CH}_{3}$ & $\mathrm{CH}_{3}$ \\
2-Acetylpyrrole & - & $\mathrm{CH}_{3} \mathrm{CO}$ & $\mathrm{H}$ & $\mathrm{H}$ \\
2-Acetyl-1-methylpyrrole & - & $\mathrm{CH}_{3} \mathrm{CO}$ & $\mathrm{H}$ & $\mathrm{CH}_{3}$ \\
Pyrrole-2-carboxaldehyde & - & $\mathrm{CHO}$ & $\mathrm{H}$ & $\mathrm{H}$ \\
1-Methyl-2-pyrrolecarboxaldehyde & - & $\mathrm{CHO}$ & $\mathrm{H}$ & $\mathrm{CH}_{3}$ \\
HMP & - & $\mathrm{CH}_{3} \mathrm{CH}(\mathrm{OH})$ & $\mathrm{H}$ & $\mathrm{CH}_{3}$ \\
DIM & 0 & $\mathrm{CH}_{3}$ & - & $\mathrm{CH}_{3}$ \\
TRI & 1 & $\mathrm{CH}_{3}$ & - & $\mathrm{CH}_{3}$ \\
TET & 2 & $\mathrm{CH}_{3}$ & - & $\mathrm{CH}_{3}$
\end{tabular}

Figure 6: Structures of the different pyrrole derivatives. HMP=2-(1-hydroxyethyl)-1methylpyrrole, DIM=dimers, TRI=trimers, TET=tetramers. Reproduced from Hidalgo et al (2003) with permission from American Chemical Society. 